\title{
El marqués de Salinas, Francisco Javier Fernández de Paredes, y su permanencia en la clase dirigente piurana a inicios de la República (1785-1839)
}

Le marquis de Salinas, Francisco Javier Fernández de Paredes, et son appartenance continue à la classe dirigeante de Piura aux débuts de la République (1785-1839)

The marquis of Salinas, Francisco Javier Fernández de Paredes, and his permanence in the leading clase of Piura in the beginning of the Republic (1785-1839)

\section{Elizabeth Hernández García}

\section{OpenEdition}

\section{Journals}

Edición electrónica

URL: http://journals.openedition.org/bifea/3586

DOI: 10.4000/bifea.3586

ISSN: 2076-5827

\section{Editor}

Institut Français d'Études Andines

Edición impresa

Fecha de publicación: 1 diciembre 2007

Paginación: 361-391

ISSN: 0303-7495

Referencia electrónica

Elizabeth Hernández García, «El marqués de Salinas, Francisco Javier Fernández de Paredes, y su permanencia en la clase dirigente piurana a inicios de la República (1785-1839) », Bulletin de l'Institut français d'études andines [En línea], 36 (3) | 2007, Publicado el 01 junio 2008, consultado el 01 diciembre 2020. URL : http://journals.openedition.org/bifea/3586 ; DOI : https://doi.org/10.4000/bifea. 3586

tentenus du Bulletin de l'Institut français d'études andines sont mis à disposition selon les termes de la licence Creative Commons Attribution - Pas d'Utilisation Commerciale - Pas de Modification 4.0 International. 


\title{
El marqués de Salinas, Francisco Javier Fernández de Paredes, y su permanencia en la clase dirigente piurana a inicios de la República (1785-1839)
}

\author{
Elizabeth Hernández García*
}

\begin{abstract}
Resumen
Francisco Javier Fernández de Paredes y Noriega, último marqués de Salinas y único título de Castilla en Piura en el período en estudio, era uno de los mayores propietarios de la región al final del período colonial, lo que le otorgaba una importante cuota de poder en su propio ámbito. Su carrera fue la del gran hacendado y comerciante; no le interesaron los cargos administrativos, no obstante proceder de un apellido que tuvo importancia en la burocracia y educación superior capitalina limeña. Con su paso a las filas patriotas y la ejecución de otras estrategias sociales y políticas, Francisco Javier consiguió mantenerse en la cúspide del poder en la Piura republicana, permitiendo al clan familiar mantener la preeminencia en una provincia y en un momento en el que era el único que representaba la conexión directa con el antiguo privilegio real.
\end{abstract}

Palabras clave: Marquesado de Salinas, partido de Piura, estrategias políticas, poder económico, independencia de Piura, Piura republicana

Le marquis de Salinas, Francisco Javier Fernández de Paredes, et son appartenance continue à la classe dirigeante de Piura aux débuts de la République (1785-1839)

\section{Résumé}

Francisco Javier Fernández de Paredes y Noriega, dernier marquis de Salinas et l'unique détenteur d'un titre de Castille à Piura pour la période qui nous concerne, était l'un des plus grands propriétaires de la

Doctora en Historia. Facultad de Ciencias de la Educación de la Universidad de Piura. Apartado 353, Piura, Perú. E-mail: ehernand@udep.edu.pe 
région à la fin de l'époque coloniale, ce qui lui conférait un pouvoir considérable. Sa carrière fut celle d'un grand propriétaire foncier et d'un commerçant; il ne fut pas tenté par les charges administratives même s'il appartenait à une famille traditionnellement impliquée à Lima dans l'administration et I'enseignement supérieur sur le plan local. Son ralliement aux patriotes et l'exécution d'autres stratégies sociales et politiques permirent à Francisco Javier de se maintenir au sommet du pouvoir dans la Piura républicaine, ce qui permit au clan familial de maintenir sa suprématie dans une province et à un moment où il était le seul à incarner l'ancien privilège royal.

Mots-clés : Marquisat de Salinas, Piura, stratégies politiques, pouvoir économique, indépendance de Piura, Piura républicaine

\title{
The marquis of Salinas, Francisco Javier Fernández de Paredes, and his permanence in the leading clase of Piura in the beginning of the Republic (1785-1839)
}

\begin{abstract}
Francisco Javier Fernández de Paredes y Noriega, the last marquis of Salinas and only holder of the title of Castilla in Piura during the studied period, was one of the most important owners of the region at the end of the colonial period, which gave him an important quota of power in his own area. His profession was a big landowner and merchant; he was not interested in administrative charges, in spite of coming from a very important family in bureaucratic society and superior education in Lima. With his transfer to the patriotic military and the execution of other social and political strategies, Francisco Javier stood in the summit of power in the republican Piura, allowing the traditional family to keep preeminence in the province at time when he was the only one who represented the direct connection with the old royal privilege.
\end{abstract}

Key words: Marquisate of Salinas, province of Piura, political strategies, economic power, independence of Piura, republican Piura

\section{INTRODUCCIÓN}

El estudio de la élite peruana y su desenvolvimiento en la época de la Independencia ha concitado la atención de muchos historiadores desde hace varios lustros, quienes han centrado sus investigaciones en el conocimiento del grupo de privilegio capitalino. Por este motivo la élite limeña en particular cuenta hasta el momento con una amplia e interesante producción bibliográfica que intenta desentrañar su comportamiento y particulares intereses en el período independentista1. Si bien la política ha sido el tema medular, los vecinos limeños han sido estudiados desde distintas perspectivas: genealogía, familia y entorno social, títulos nobiliarios, relaciones económicas, vínculos de poder, etc. No ha ocurrido lo mismo con las élites de provincia. A excepción de muy contados estudios sobre las élites trujillana, arequipeña y moqueguana en concreto2, las

1 El momento de quiebre en la interpretación de estas actitudes fue el clásico estudio de Heraclio Bonilla, en el año 1972, del cual se ha podido revisar la segunda edición (Bonilla \& Spalding, 1981). A partir de este momento, la producción bibliográfica se incrementó significativamente en esta perspectiva de análisis. Ver producción de Timothy Anna (2003), Scarlett O’Phelan (2001), Cristina Mazzeo (1999), Paul Rizo-Patrón (2002), Jesús Turiso Sebastián (2002), entre otros.

2 Para el caso trujillano, véase Aljovín de Losada \& Rizo-Patrón, 1998. Para el caso arequipeño, Aquerreta, 2001. Para el caso moqueguano, Cañedo-Argüelles, 2000; 2004; entre otros. 
investigaciones sobre otros grupos de privilegio del virreinato peruano en la Independencia se encuentran aún en ciernes.

Para el caso piurano, se ha incidido sobre todo en la capacidad de comercialización y en la posesión de tierras y haciendas de estos privilegiados vecinos. Se echa en falta el análisis de ese paso que la élite piurana en conjunto dio hacia el nuevo sistema propugnado por San Martín. En ese intento, el tema central de este artículo es la capacidad de adaptación de la vecindad piurana en su conjunto al sistema republicano, la perpetuación de su situación en la privilegiada minoría de esta ciudad, los mecanismos que puso en ejecución para conseguirlo; todo ello se analizará desde la trayectoria vital del miembro más destacado de aquella élite por su origen capitalino, por el ascendiente familiar en el virreinato peruano y en el entorno piurano, por su poder económico y por ser título nobiliario. Francisco Javier Fernández de Paredes representaba en Piura el escalón más alto al que la vecindad americana podía llegar, pero que, para los demás miembros de la élite de esta ciudad de provincia, era sencillamente inaccesible. Fernández de Paredes vivió el momento de quiebre que supuso la presencia de José de San Martín, y, no obstante su consagrado monarquismo, murió en su hacienda Tangarará sin haber perdido absolutamente nada en esos años, y al contrario, habiendo incrementado sus intereses económicos y su figuración social. La coyuntura de inestabilidad política que siguió a la proclamación de independencia de Piura y luego de Lima, reforzó los lazos de poder en el entorno y en el extremo norte peruano de este concreto grupo de privilegio provinciano, y mucho más, del personaje en cuestión. Su historia familiar es fundamental en nuestro intento de analizar el comportamiento del marqués de Salinas en este conflictivo momento.

\section{LOS FERNÁNDEZ DE PAREDES EN EL ÁMBITO VIRREINAL PERUANO}

Tanto el apellido como el marquesado proceden de Lima, no de Piura. Sin embargo, apenas hay rastros de uno y otro en la historiografía peruana, quizás porque, a pesar de estar presentes en instituciones como la audiencia o la universidad de San Marcos, su trayectoria social y económica fue siempre colateral a los grandes nobles y comerciantes que constituyeron la esfera principal de la élite de la capital (ver anexo 1).

La familia limeña que precedió a los Fernández de Paredes en el título tuvo conexión con la élite piurana del siglo XVI, en concreto, con el apellido Sojo, presente en Piura desde el tiempo de la conquista. Lamentablemente el conocimiento detallado de estas vinculaciones, así como de la importancia económica y social de los Sojo, se han diluido en el transcurso del tiempo, por lo que únicamente se puede recurrir a la sucesión del título nobiliario y a muy contados documentos para explicar la relación entre la élite periférica piurana y la capitalina limeña en este título de Castilla.

Según Rubén Vargas Ugarte, los marqueses de Salinas fueron: José de Echarri, a quien le sucedió su hija Mauricia de Echarri y Sojo; posteriormente heredó el título su hijo Manuel Fernández de Paredes y Echarri, de quien pasó luego a José Fernández de Paredes y Molleda; siendo finalmente Francisco Javier Fernández de Paredes el último marqués de Salinas (Vargas Ugarte, 1965: 18)3.

3 No obstante, la documentación nos habla de dos marqueses más, Tomás y Gregorio Fernández de Paredes, hermanos, en tanto que, muerto el padre, los hijos en orden de nacimiento pasaban en la práctica a ser marqueses de Salinas. 
La documentación nos dice que en el siglo XVI llegó a Piura el capitán Francisco de Sojo, quien contrajo nupcias con Catalina Cornejo de Cantoral. Hijo de ambos fue Juan de Sojo y Cantoral, que heredó de su padre las haciendas Sojo y Capilla. Juan se casó con Rosa de Olavarrieta y Medrano (Moya Espinosa, 1981-1984: n. 505). Dos hijas de este matrimonio enlazaron con dos navarros de Puente la Reina: María Catalina lo hizo con José de Echarri, el 2 de febrero de 1707, y Josefa Gabriela con Diego de Echarri, en 1710 (Ramos Seminario \& Garrido Lecca, 1996: 76).

Con José de Echarri, la familia Sojo piurana ascendió al rango de élite nobiliaria, al recibir el título de marqués de Salinas el 14 de febrero de 1711. Gobernador y capitán general de Buenos Aires, caballero de Santiago, gentilhombre de cámara de su majestad y primer marqués de Salinas4, José de Echarri y María Catalina de Sojo constituyeron un matrimonio de suma importancia económica y administrativa, como lo demuestra la suma de 60000 pesos con que dotaron a su primogénita y heredera del título, Rosa Mauricia de Echarri y Sojo, para contraer nupcias con el limeño Francisco Fernández de Paredes y Clerques. Esa cantidad procedía de la venta de tres corregimientos, propiedad de José de Echarri: el de Cusco y el de Saña, valorados ambos en 25000 pesos, adquiridos por Francisco Arias de Saavedra y Juan Miguel de Oteiza6, respectivamente, y el de Larecaja, que lo adquirió Sebastián Diez en 35000 pesos. Además, Rosa Mauricia llevó al matrimonio varias alhajas y esclavos (AGN, 1762, serie: notarial. Notario: Agustín Gerónimo de Portalanza. Prot. 871: fol. 30). El matrimonio se realizó en la ciudad de Trujillo el 21 de octubre de 1720 (Lohmann, 1947, II: 325). Francisco Fernández de Paredes, marqués consorte, fue alcalde de Lima en 1735 y 1736; destacó también como capitán de mar y guerra de las fuerzas que acudieron a la defensa de Panamá contra el pirata Vernon.

De los Echarri y de los Fernández de Paredes hay pocas referencias en la historiografía?. La documentación los sitúa como uno de los apellidos económicamente de mediana importancia en Lima, con un caudal que no llegaba al de las grandes fortunas de la capital virreinal y con cierta presencia en el ámbito cultural del reinos. Sin embargo, en la burocracia virreinal tuvieron significativa importancia, pues, como afirma Guillermo Lohmann, la familia Fernández de Paredes monopolizó el cargo de Secretario Mayor de Gobernación del virreinato del Perú durante prácticamente todo el siglo XVIII hasta la reversión de la dignidad a la Corona en 1791. Así el capitán Francisco Fernández de Paredes y Sánchez Cortés, en 1703, ostentaba este nombramiento; le siguió alrededor de 1709 su hijo Francisco Fernández de Paredes y Sánchez de Arévalo (Lohmann, 2004: 192)

4 AHN, 1789, Órdenes Militares: Expedientillos, n. 8506. Puede verse también Vargas Ugarte, 1965.

5 La media dotal en Piura en la época colonial era, aproximadamente, de 4000 pesos en dinero en efectivo y bienes (Hernández García, 2003: 150).

6 Tras el fallecimiento de Echarri, María Catalina de Sojo y Olavarrieta, contrajo segundas nupcias en 1721 con Juan Miguel de Oteiza y de Ubiria, también navarro, de Sumbilla (Ramos Seminario \& Garrido Lecca, 1996: 121)

7 Tenemos referencia de una historia genealógica de los Fernández de Paredes que fue realizada en el siglo XVIII por uno de los descendientes de esta familia, pero no ha podido ser revisada. Agradezco este dato proporcionado por D. Alberto Arrese Vásquez de Velasco.

8 Uno de los ascendientes de esta familia, Gregorio de Molleda y Clerque, doctor en Cánones por la Universidad de San Marcos, tuvo una relevante carrera eclesiástica: prebendado de la catedral limeña, viajó a Roma como procurador del cabildo en la causa de canonización de Santo Toribio de Mogrovejo. Consagrado obispo de Yzauria por el Papa Benedicto XII en la capilla de su Palacio Quirinal, prelado doméstico del Papa, obispo de Cartagena, de Trujillo y arzobispo de la Plata (Eguiguren, 1940, I: 542). 
heredando el cargo en 1763 su hijo Francisco Fernández de Paredes y Clerque, marqués consorte de Salinas, quien desembolsó 36000 pesos por dicho oficio9.

El primogénito de Francisco y Rosa Mauricia, Manuel Antonio Ubaldo, fue el primero en unir el título en propiedad al apellido Fernández de Paredes. Manuel era teniente coronel de los Reales Ejércitos, sargento mayor del batallón provincial de milicias de infantería española de Lima y, además, escribano mayor de la gobernación y guerra del reino del Perú, oficio que ostentaba su padre. Tenía, por tanto, una posición muy relevante en la alta burocracia virreinal. Fue el último titular de la Secretaría Mayor de Gobernación, heredando el oficio de su padre Francisco Fernández de Paredes y Clerque, cargo que adquirió en 73000 pesos. Sin embargo, perdió algunos derechos propios de este cargo al crearse el virreinato de Buenos Aires y al establecerse el sistema de intendencias en el Perú (AGN, 1803, Superior Gobierno. Leg. 45. Cuad. 603). Por Real Orden del 28 de diciembre de 1803, la Secretaría de Gobernación quedó incorporada a la Corona, confiándose su administración a José Miguel Sánchez Navarrete, que abonó por el empleo 38058 pesos (Lohmann, 2004: 200)10.

En 1760, Manuel Antonio salió elegido alcalde ordinario de Lima. También fue suya la escribanía mayor de Buenos Aires, que adquirió de José Sensano por 6360 pesos (Milla Batres, 1986, IV: 17). Recibió el título de caballero de Santiago en 1789 (AHN, 1789, Órdenes Militares: Expedientillos, n. 8506), y, finalmente, alcanzó honores de consejero en el Supremo Consejo de Hacienda.

Manuel Antonio quiso preservar el relativo caudal familiar así como la importancia social del apellido. Contrajo matrimonio en 1745 con una criolla limeña, Evarista Geldres y Molleda, tía suya en tanto que era hermana de la segunda esposa de su padre. Los hijos de este matrimonio, Tomás, Manuel Antonio, Juan, Gregorio y José, tuvieron otros referentes de nobleza, así como también presencia económica en la capital extendiendo, alguno de ellos, su radio de acción a la periferia virreinal y a la península. Juan Fernández de Paredes y Geldres, por ejemplo, fue caballero de la orden de Carlos III. Entabló vínculos de parentesco con la nobleza limeña al casarse con Francisca Carrillo de Albornoz y Salazar, hija de los condes de Montemar y Monteblanco (AGN, 1803, serie: notarial. Notario: Morel de la Prada. Prot. 437). Con estas nupcias, Juan fortaleció la presencia de los Fernández de Paredes, así como de los sucesivos marqueses de Salinas, dentro de la endogámica élite limeña colonial.

Gregorio Fernández de Paredes, también caballero de la orden de Carlos III, siguió la carrera eclesiástica. Inició sus estudios en el Seminario de Santo Toribio, de donde pasó al Convictorio de San Carlos, y de este a la Universidad de San Marcos, donde obtuvo el Doctorado en Sagrada Teología. Se desempeñó como vicario y cura de los curatos de Reyes y Pallanchacra (Tarma) en el Arzobispado de Lima (Lohmann, 1947, I: 34). Tuvo un hijo natural, José Gregorio que fue profesor de medicina, catedrático de Prima de Matemática y de Geometría en la Universidad de San Marcos; además, fue cosmógrafo mayor del reino y tuvo a cargo la publicación de la Gaceta de Gobierno de Lima en el año 1810 (AGI, 1815, Lima, 749). Finalmente, a inicios de la etapa republicana, fue elegido diputado propietario por Lima en el Primer Congreso Constituyente del año 1822.

9 De esos 36000 pesos, canceló únicamente la mitad; los restantes fueron «legados» a Manuel Antonio, su hijo, como deuda a pagar en su nombre (AGN, 1762, serie: notarial. Notario: Agustín Gerónimo de Portalanza. Prot. 871: fol. 30).

10 Sobre la importancia social y económica de la familia Sánchez Navarrete, véase Hernández García, 2005a: 446-450. 
El primogénito de Manuel Antonio Fernández de Paredes y de Evarista Geldres y Molleda, Tomás, fue el que directamente se relacionó con el espacio norte virreinal peruano desarrollando una trayectoria al margen de los ámbitos académicos en los que estuvo inmerso el resto de sus parientes. Gracias a los lazos que fue estrechando en el norte, el título nobiliario tuvo mucho que ver con la historia del corregimiento y posterior partido piurano. Tomás inició en Piura toda una tradición nobiliaria y de poder económico.

\section{TOMÁS FERNÁNDEZ DE PAREDES EN EL PARTIDO DE PIURA}

Al crearse el virreinato del Río de la Plata en 1776, Manuel Antonio Fernández de Paredes designó a su primogénito, Tomás, para desempeñarse como Secretario de Gobernación en la nueva circunscripción (Lohmann, 2004: 203). Sin embargo, no consta en ninguno de los documentos notariales de este último, haberse hecho cargo en algún momento de dicho oficio. Antes bien, nacido en la ciudad de Trujillo, con Tomás el apellido Fernández de Paredes adquirió presencia efectiva y gran influencia en el partido de Piura.

No sabemos a ciencia cierta las razones de su establecimiento en esta ciudad pero todo apunta a un gran interés económico por parte de la familia Fernández de Paredes en hacerse presente en este espacio mercantil que, para el siglo XVIII, había adquirido una gran importancia dentro del conjunto económico virreinal. La producción de las haciendas, la cercanía respecto a los lugares de extracción de la preciada cascarilla, así como la puerta de entrada y salida, de control, que suponía el puerto de Paita, concitaron la atención de los grandes mercaderes capitalinos11. Definitivamente, como se verá, las razones económicas se reafirman como las más poderosas en ese traslado de Tomás al norte, pues Piura ofrecía a esta familia nulas expectativas de ascenso social y sí grandes beneficios mercantiles.

Pero los intereses ya estaban dados de antemano, pues Piura era el lugar de nacimiento de Rosa de Sojo y Olavarrieta y de Mauricia de Echarri y Sojo, bisabuela y abuela paternas de Tomás, respectivamente; así que no resulta extraño que los Fernández de Paredes se sirvieran de esta conexión para reforzar su posición económica. Paulatinamente, entonces, Tomás se fue posicionando en este espacio norteño, adquiriendo en 1773 la hacienda Tangarará, ubicada en el valle del Chira, de un tío abuelo suyo, Juan Eduardo de Oteiza y Sojo, albacea de Francisco de Sojo, en 15000 pesos 12 . Compró, además, el potrero y tierras de la otra banda de Tangarará, que se conocía por el nombre de «Sojo». Con Tangarará tuvo ya el inicio del control de una parte importante del valle del Chira; poder económico que heredaron los poseedores siguientes. Aunque no se desconectó de la capital virreinal —viajó con frecuencia a Lima por razones familiares o de negocios-, Tomás se estableció finalmente en Piura.

Desde el punto de vista social y económico, Tomás fue un punto de mira en el partido piurano. Sin embargo, casi al final de su vida, también quiso añadir otro referente de nobleza en el servicio a la corona: las milicias. En 1797, Tomás fue nombrado Coronel del

11 Al respecto, ver producción bibliográfica de Susana Aldana (1999), Alejandro Reyes (1999) y Luis Miguel Glave (1993). También la documentación archivística brinda reiteradamente ejemplos de la conexión de mercaderes limeños con el espacio piurano a lo largo de todo el Virreinato; inclusive el Tribunal del Consulado de Lima tuvo siempre presente el devenir económico de la provincia y de sus comerciantes (Hernández García, en prensa).

12 Los 15000 pesos se pagaron en dos partes y modos: 12714 pesos en efectivo, y por la restante cantidad, se entregó un instrumento de reconocimiento a favor de un aniversario, «fundado por el dicho D. Juan Eduardo por voluntad de Da. Rosa de Olavarrieta». Esta última era su tatarabuela paterna (AGN, 1803, serie: notarial. Notario: Gervasio de Figueroa. Prot. 244: fol. 65). 
Regimiento de Caballería del partido de La Chira (AGS, 1797, Secretaría de Guerra. Leg. 7134. Exp. 109); y a inicios del siglo XIX, coronel de dragones de la ciudad de Piura. EI nombramiento de coronel del regimiento de caballería del partido de La Chira, al parecer, fue consecuencia de sus pertinentes contactos y relaciones personales con otros miembros importantes del estamento privilegiado piurano, en claro enfrentamiento de intereses con el principal contendor, Gregorio Javier Espinosa de los Monteros, el comerciante por antonomasia del partido.

Espinosa mantenía estrechas relaciones económicas con Tomás Fernández de Paredes. En el año 1789 arrendó una parte grande de la hacienda Tangarará por 2000 pesos (ARP, 1789, serie: notarial. Notario: José Miguel Zavala y Castilla. Prot. 5. Leg. 54: fol. 125). Para ese entonces, Tomás destacaba como el hijo de los marqueses de Salinas y dueño de aquella hacienda, «títulos» muy importantes; mientras que Gregorio, aparte de su conocido auge mercantil, tenía larga trayectoria en el mando de las milicias piuranas, por lo que esperaba ser ascendido a esa coronelía. En algún momento, esa buena relación entre ambos se truncó y las desavenencias salieron a la luz con el ingreso de Tomás al mando de las milicias ${ }^{13}$. Gregorio escribió al Consejo de Indias que:

«En el nombramiento de dicho Paredes no se ha hecho otra cosa que autorizarlo para que, por la enemistad que me profesa muy de antemano, y que con la contradicción que he hecho se ha redoblado, y en todo lo que se le presente me mortifique...» (AGS, 1797, Secretaría de Guerra. Leg. 7134. Exp. 109) (La cursiva es nuestra).

Efectivamente, el nombramiento de Tomás era inesperado teniendo en cuenta el desempeño de Gregorio al frente de las milicias, las que fueron consideradas como las mejores de todo Piura. Por ello, el virrey Manuel de Guirior, a su arribo a Paita, le concedió el nombramiento de Capitán de Dragones de la ciudad de Piura14.

El inesperado nombramiento de Tomás nos permite apreciar su influencia tanto en el entorno del partido como con las autoridades de la capital, de las que debió salir, en definitiva, la recomendación para obtener aquel mando. Debió de contar desde luego con el decisivo apoyo de Gabino Gainza, en ese entonces Teniente Coronel de Ejército y Comandante General de la costa norte 15 , que era quien proponía esos nombramientos, y muy probablemente también con el de Vicente Valdivieso y de Joaquín de Helguero y Gorgoya, cuya importancia en el partido era innegable. Valdivieso era uno de los hacendados y comerciantes más importantes de inicios del siglo XIX; y el peninsular Joaquín de Helguero, también comerciante, fue nombrado Juez Diputado de Comercio por el Consulado de Lima, entre fines del siglo XVIII y principios del XIX (Hernández García, 2005b: 198).

Pero otro aspecto importante sale a la luz con este enfrentamiento: Tomás Fernández de Paredes se nos muestra en el día a día como un hacendado intransigente, despótico, cruel inclusive, con un poder casi omnímodo e irresistible en el partido, como si estuviera seguro

13 Sorprende el nombramiento, además, porque cuando se le adjudica Tomás estaba muy enfermo. Como «hético» lo define Gregorio Espinosa; de hecho, Tomás muere cinco años después, en 1802.

14 Gregorio Espinosa servía en las milicias piuranas desde el año 1771 hasta 1779 de Capitán de Infantería de la Compañía Suelta de los pueblos de Paita, Colán y Amotape; y desde 1779 hasta 1781, sirvió la Capitanía de Dragones de Piura, de la que se le ascendió a la Capitanía Comandante del pueblo de Amotape, empleo que servía cuando en 1797 elevó su reclamo (AGS, 1797, Secretaría de Guerra. Leg. 7134. Exp. 109: fol. 7v-12v).

15 Gaínza, que luego tuvo un importante papel en la primera fase emancipadora de Chile, era Caballero de la Orden Hospitalaria de San Juan (ARP, 1797, serie: Intendencia - Causas Criminales. Leg. 57. Exp. 1072: fol. 87). Su relación con Tomás Fernández de Paredes debía ser muy estrecha, pues en su testamento lo deja como su apoderado para resolver asuntos de la testamentaría de Manuel Fernández de Paredes, padre de Tomás (ARP, 1802, serie: notarial. Notario: Antonio del Solar. Leg. 113). 
que nadie en su entorno le podía hacer frente. La relación arbitraria de la élite con el «pueblo» se evidencia con creces con la siguiente acusación de Gregorio:

«... por su genio indócil y feroz, [Tomás] ha tenido avasallados a los miserables, azotando a gentes libres y aprisionándolas a su arbitrio, quemando casas de sus colonos si le han retardado la satisfacción del arriendo, y exigiéndoles en pago de ello los frutos por la mitad de su valor, sin que hayan podido reclamar por su constitución infeliz y miserable...» (AGS, 1797, Secretaría de Guerra. Leg. 7134. Exp. 109: fol. 2v).

Los colonos de su hacienda eran personas sin recursos que trabajaban para cultivar la parte que se les arrendaba y así poder subsistir. Esto, como ellos mismos lo dicen, era una realidad generalizada en toda la provincia ${ }^{16}$. Esa dependencia se evidenciaba, precisamente, en la tropa miliciana que Tomás, contra ordenanza, reclutaba de su hacienda, convirtiéndose, como lo afirma el documento, en un «señor de vasallos» (AGS, 1797, Secretaría de Guerra. Leg. 7134. Exp. 109).

En el año 1858, el importante hacendado José de Lama17 afirmó que Tomás fue el primer usurpador de las tierras de Morropón, «... abusando del influjo que le daban su fortuna y su empleo de Coronel...» y sirviéndose de «... hombres ignorantes, tímidos, aviesos, que tiemblan delante del poderoso...» («Deslinde de Morropón», 1890: fol. 8-9). Pero ese poder de mando no excluía a las autoridades del lugar, pues el triunfo sobre Gregorio se dio por las conexiones y el gran respeto que inspiraba a «... las justicias y condecorados» de este vecindario (ARP, 1797, serie: Intendencia - Causas Criminales. Leg. 57. Exp. 1072: fol. 92). El «genio indócil» de Tomás se manifestó en la quema de una capilla en la década de 1790, hecho grave que no tuvo sanción a pesar que las autoridades eclesiásticas lo excomulgaron; eso no hizo mella en él, antes bien, el marqués «se vanagloria de la quema de la iglesia...» (AGS, 1797, Secretaría de Guerra. Leg. 7134. Exp. 109).

Este despótico modo de proceder fue una constante en los sucesores del mayorazgo y posteriores marqueses de Salinas, realidad no tan difícil de comprender, en tanto que se trataba de personas que concentraban los más altos referentes de encumbramiento social que se podía conseguir en la América hispana; eran los dueños y señores de la tierra y de los colonos a su cargo, eran mirados, por ello, con respeto y con temor. Demasiado poder para una sola persona. La educación que podían recibir fortificaba más las murallas de separación de los grupos socioeconómicos, mucho más en un entorno en el que la dependencia hacia los hacendados podía ser absoluta. Este comportamiento también formaba parte de la «tradición heredada»; así, cuando José de Lama realizó la acusación antes mencionada, lo hizo en medio de una disputa legal con Gaspar Vásquez de Velasco, yerno del último marqués, por similares razones que sesenta años atrás se le hicieron a Tomás: carácter despótico y posesión ilícita de tierras valiéndose del temor de la población hacia toda la familia.

A pesar de éstas y otras revelaciones, Tomás conservó el mando de las milicias piuranas hasta el final de sus días. El único ámbito que parece no le interesó fue el de la política local. No consta que haya formado parte del cabildo de Piura, a pesar de su condición de único titulado del partido, coronel de sus milicias y el hacendado de mayor relevancia.

16 «... nuestras personas e hijos siempre se han valido a tomar en arriendo de los hacendados de esta provincia un terreno de tierras de humedad para, a costa de su trabajo, cultivarlos y mantenerse de sus sembrados» (ARP, 1797, serie: Intendencia-Causas Criminales. Leg. 57. Exp. 1072: fol. 90).

17 José de Lama fue uno de los hacendados más importantes de la naciente República. Contaba con extensas propiedades, entre las cuales destacaba La Brea y Pariñas, lugar que posteriormente se convirtió en el centro de toda la actividad petrolera del Perú. 
Una última prueba de su capacidad económica la da el hecho de haber sido uno de los pocos piuranos — además de los Sánchez Navarrete, en el siglo XVIII—que consiguió hacer el costoso viaje a la península, que sepamos, en dos ocasiones. La primera alrededor del año 1766, cuando portaba un memorial de su hermano Manuel para suplicar mercedes a Carlos III por sus méritos y servicios ${ }^{18}$. La segunda, a mediados de la década de 1780, quizás por negocios mercantiles (AGI, 1783, Contratación, 5526, n. 1: r.18)19.

El mayorazgo así como el título nobiliario recayeron en él al fallecimiento de su padre por ser el primogénito (ver anexo 2). Esto debió suceder a inicios del siglo XIX, que es cuando Tomás figura como marqués de Salinas. No se casó ni consta que tuviera descendencia reconocida, razón por la cual el título nobiliario no se quedó en Piura sino que volvió a la capital virreinal tras su fallecimiento el 28 de septiembre de 1802.

$\mathrm{Al}$ año siguiente, su hermano Manuel tuvo que solicitar la revalidación del título al Consejo de Indias, pues a Tomás no le dio tiempo de pagar los derechos correspondientes, por lo que, en teoría, aunque se titulase «marqués», legalmente nunca fue noble titulado20; la corona le concedió a Manuel el marquesado en 1806. Aunque residía en Lima, Manuel consiguió manejar muy bien los poderosos intereses económicos de su familia en Piura. Tampoco tuvo descendencia directa, así que el título recayó posteriormente en su hermano, José Fernández de Paredes y Molleda, quien logró establecer nuevos e interesantes vínculos sanguíneos en la ciudad de Lima.

La fortuna piurana de Tomás pasó, como veremos, a un sobrino suyo. José, tercer marqués de Salinas, no disfrutó por ello del mismo bienestar económico21. Su relevante posición en la sociedad limeña se debió a ser hijo de los marqueses de Salinas y a su carrera de letrado. Ambos elementos le posibilitaron un matrimonio ventajoso, en concreto con Manuela de Noriega y Domínguez, vecina limeña. Esta unión reforzó la conexión de los Fernández de Paredes con la más antigua nobleza titulada del reino y la presencia de sus miembros en el ámbito cultural y en la alta burocracia capitalina.

En efecto, Manuela de Noriega y Domínguez era hija del hidalgo asturiano Pedro de Noriega y de Manuela Domínguez y Murga, criolla limeña que se decía descendiente de Pedro de Valdivia22.

18 «... Manuel Fernández de Paredes, residente en esta Ciudad de los Reyes del Perú, otorgo que doy todo mi poder... al Dr. Tomás Fernández de Paredes, mi hermano, de partida para la Corte de Madrid en el navío de S.M. nombrado «El Peruano», para que en mi nombre... comparezca ante la católica Majestad del Rey Nuestro Señor D. Carlos III... pida y suplique que en remuneración de mis méritos y servicios, los de mis padres y demás antepasados, se me hagan cualesquiera mercedes de las que S.M. provee para estos Reinos y Provincias del Perú, así en materia de gracia como de justicia...» (AGN, 1766, serie: notarial. Notario: Valentín Torres Preciado. Prot. 1067: fol. 500v).

19 Licencia de embarque para Tomás Fernández de Paredes, en la que consta que ha pagado los derechos de almojarifazgo.

20 Manuel afirma: «... que aunque a la sucesión de él [del marquesado de Salinas] debió haber estado su hermano D. Tomás Fernández Paredes como hijo primogénito, no se verificó por su inmediato fallecimiento, razón por que había recaído en el exponente [Manuel] dicho título como hermano y sucesor inmediato de aquél...» (AGI, 1804, Títulos de Castilla, 8).

21 En su testamento afirma: «... declaro por mis bienes la parte materna que por legítima sucesión me toca y pertenece en la dote que llevó dicha mi madre al matrimonio, y en los bienes que quedaron por su fin y muerte, de los que hasta el presente no se ha hecho división y partición, ni a mí se me ha dado cosa alguna...» (AGN, 1783, serie notarial. Notario: Julián de Cubillas. Prot. 581).

22 Noriega era natural del lugar de la Borgolla, montañas de Oviedo (AGN, 1765, serie: notarial. Notario: Felipe José Jaraba. Prot. 554: fol. 14). En otro lugar se informa de la ascendencia de uno y otro: «D. Pedro de Noriega y Noriega Inguanzo, y de Da. Manuela Domínguez y Murga; de distinguida calidad por ambas líneas, enlazado por la paterna con el Marquesado de Hermosilla, propia de la casa de Noriega... y 
La familia de la esposa no parece que aportara un gran capital23, pero sí los contactos y el entorno en el que se desarrolló la carrera como jurista de José. Llegó a ser Doctor en Cánones y Leyes por la Universidad de San Marcos y relator propietario de la Audiencia de Lima (AGN, 1783, serie: notarial. Notario: Julián de Cubillas. Prot. 581: fol. 438v). Su cuñado Manuel Antonio de Noriega y Domínguez fue uno de los más destacados juristas del Virreinato en la última etapa colonial, lo que le valió ser elegido Diputado suplente a Cortes por la intendencia de Lima y partidos de su comprensión, en el año 181024. Su hermano Francisco también fue doctor en Leyes por la Universidad de San Marcos; sirvió durante doce años la plaza de relator de la junta superior de real hacienda y falleció en el destino de Teniente Asesor Interino de la intendencia de Arequipa (AGI, 1811, Lima, 741, n. 91).

José y Manuela tuvieron dos hijos, Francisco Javier y José. Este último se quedó en Lima, donde contrajo matrimonio con su prima María del Carmen Noriega y Zenzano (AGN, 1847, serie: notarial. Notario: Juan Cosío. Prot. 160; 1814, serie: notarial. Notario: Ignacio Ayllón Salazar. Prot. 22). Francisco Javier, en cambio, escribió una historia particular, fuera de su ciudad de origen, al igual que su tío Tomás, en el distante partido de Piura, como se verá en los apartados siguientes.

\section{FRANCISCO JAVIER FERNÁNDEZ DE PAREDES: ÚLTIMO MARQUÉS EN LA PIURA VIRREINAL}

Tomás Fernández de Paredes llegó a establecer en Piura una relación muy estrecha con los apellidos importantes del entorno local. Uno de sus amigos más entrañables fue Manuel Francisco de Carrión y Merodio, casado con Josefa de Irarrázabal y Andia; con ésta debió tener mucha confianza, pues no solo la nombró su albacea testamentaria y patrona de la fundación piadosa — una capellanía dotada con un censo de 10000 pesos— para la celebración de las misas de aniversario, sino que le dejó la administración de todos los bienes, fincas y de la hacienda Tangarará por el tiempo que ella considerase conveniente. Además, Tomás dejó a Josefa algunas disposiciones testamentarias más que condicionaron la vida en Piura del último marqués de Salinas asegurándole su porvenir.

\section{1. Su establecimiento en el partido de Piura}

Tomás nombró sucesor del mayorazgo al hijo mayor de su hermano José, es decir, a Francisco Javier Fernández de Paredes y Noriega, y a sus descendientes. Acabada esta línea sucesoria, continuaría la de sus hermanos e hijos. Con esta disposición, Tomás le aseguró

procedente por la materna del Adelantado Pedro de Valdivia, pacificador y poblador y capitán general que fue del reino de Chile...» (AGI, 1811, Lima, 741, n. 91).

23 El albacea testamentario de Pedro de Noriega Inguanzo menciona como avalúo total de sus bienes, la cantidad de 94744 pesos; poco dinero inclusive para un vecino piurano de la élite (AGN, 1765, serie: notarial. Notario: Felipe José Jaraba. Prot. 554: fol. 15).

24 Nació en Lima en el año 1758. Recibido de abogado en la audiencia limeña en 1778, se doctoró en Cánones y Leyes el año siguiente. Entre 1777 y 1810 ocupó las cátedras de Decreto, Instituta, Código, Vísperas de Cánones y Derecho Graciano en la Universidad de San Marcos. Llegó a ser Decano del Colegio de Abogados de Lima. En 1811, tras haber obtenido la elección de diputado, solicitó la toga o, en su defecto, la plaza de Asesor General o la de Auditor de Guerra del Virreinato, sin éxito (AGI, 1811, Lima, 741, n. 91: fol. 2-12). Falleció el 19 de febrero de 1814 a bordo del navío portugués «Lord Wellington» en el que viajaba a la península como diputado electo (AGN, 1814, serie: notarial. Notario: Ignacio Ayllón Salazar. Prot. 22: fol. 1871). 
a Francisco Javier — tal vez sabiendo que sobre él recaería el marquesado de Salinas - un vínculo. En segundo lugar, y lo más importante, Tomás dejó establecido un conveniente arreglo, como lo explica Josefa de Irarrazábal, su albacea:

«... declaro haberme comunicado el testador procurase tuviera efecto el matrimonio que tiene tratado de su sobrino D. Francisco Javier Fernández de Paredes y Noriega, hijo mayor de su hermano el Sr. Dr. D. José Paredes, con Da. María de la Cruz Carrasco y Carrión, sobrina de mi difunto esposo, y que a este fin lo hiciese ir de esta capital a Piura, cuya diligencia la tengo practicada, y espero en breve la noticia de haberse verificado el matrimonio...» (AGN, 1803, serie: notarial. Notario: Gervasio de Figueroa. Prot. 244: fol. 65).

María de la Cruz Carrasco y Carrión era hija de los piuranos Manuel Gregorio Carrasco y María Mercedes Carrión e Iglesia, la misma familia con la que Tomás había establecido vínculos décadas antes - fue testigo de matrimonio de Joaquín de Helguero con Juana Josefa de Carrión e Iglesia en el año 1797- y a la que pertenecía el importante eclesiástico Francisco Félix de Carrión e Iglesia25; todos miembros de la élite hacendada, mercantil y letrada del lugar.

El concertado matrimonio con María de la Cruz fue el motivo por el que Francisco Javier dejó todo y se trasladó a vivir definitivamente en Piura. De esa manera, el marquesado de Salinas, que se inició con un típico matrimonio entre peninsular y piurana, terminó con Francisco Javier en tierras de esa misma jurisdicción. Esto, que pudiera ser una casualidad, es muy posible que fuese algo preparado por Tomás: al ser el único miembro del clan Fernández de Paredes residente casi toda su vida en Piura, tenía, de hecho, mayor cercanía, cariño y simpatía con la rama piurana de su apellido que con la limeña. Tomás se había hecho vecino en Piura, ello suponía toda una suerte de relaciones afectivas que podían superar los vínculos del paisanaje, proceso que de hecho ocurría con casi todos los peninsulares. En este asunto tan delicado — el legado del mayorazgo- no sorprende entonces, que haya pensado que el descendiente en el título se vinculase a esta tierra. Sin embargo, no se descarta una razón de índole económica unida a la de matiz afectivo. Tomás había experimentado las enormes posibilidades que la región piurana podía ofrecer. Resumiendo mucho, él había obtenido la hacienda más fértil del valle del Chira, Tangarará; se había posesionado de terrenos que incrementaban su poder y sus ganancias; había viajado dos veces a la península; y, tenía en sus manos el control militar de localidades muy importantes. Pero para conseguirlo había que empezar de cero; por eso, quizá, pensó en su joven sobrino y no en sus hermanos, Manuel y José, que fueron marqueses también, pero que ya tenían una vida hecha en la capital del Virreinato26.

Consciente de la predilección de Tomás por su sobrino Francisco Javier, y que le venía preparando una fuerte posición en el lugar, nada más efectuarse las nupcias, Josefa Irarrazábal renunció a favor de su sobrina María de la Cruz al patronato de la capellanía y

25 Francisco Félix de Carrión era uno de los letrados eclesiásticos piuranos de mayor importancia a finales del período virreinal en el Perú. Doctor en Cánones y Leyes por la Universidad de San Marcos, fue asesor de varias autoridades civiles y militares en el espacio norte peruano; contribuyó en la pacificación de la sierra trujillana en los primeros años del siglo XIX; fue requerido para elaborar el plan de defensa de la ciudad de Piura el año 1809, ante la amenaza de la revolución en Quito; finalmente, fue nombrado canónigo de la iglesia catedral de Lima y docente de la Universidad de San Marcos, muriendo en 1823 sin recibir retribución monetaria por su beneficio eclesiástico, pues la revolución de la independencia trastocó todo el orden existente (Hernández García, 2006: 32-45).

26 El ejemplo claro lo tenemos en Manuel, hermano de Tomás: siendo dueño de la hacienda Morropón, la administración directa corría a cargo de otra persona; no consta ningún viaje de Manuel a Piura (ARP, 1806, serie: Intendencia-Causas Administrativas Ordinarias. Leg. 51. Exp. 964: fol. 7v). 
a continuar administrando los bienes de Tomás, que ahora pasaban a propiedad directa de Francisco (AGN, 1803, serie: notarial. Notario: Gervasio de Figueroa. Prot. 244: fol. 66); entre estos bienes se contaban las productivas haciendas Tangarará y Morropón; heredaba, así, una impresionante cuota de poder en la región.

Francisco Javier nació en Lima en el año 1785, ciudad en la que residió hasta su traslado a Piura en 1803, un año después de fallecer su tío Tomás. A diferencia de sus ascendientes inmediatos, no se le destinó a la carrera educativa o cultural de la capital. Probablemente porque se le tenía por el más probable sucesor en el título, su familia le consiguió una tenencia de las milicias de caballería de nobleza de Lima, en noviembre de 1798. Con apenas veinte años se convirtió en heredero del mayorazgo y bienes de los Fernández de Paredes en Lima y Piura. Aquí destacó por sus actividades económicas y por su presencia en la esfera política local, convirtiéndose en uno de los vecinos más influyentes del partido en todos los ámbitos. En el plano económico, por tanto, Francisco Javier se estableció en Piura sobre una base más que sólida. La hacienda Tangarará le brindó renombre y bonanza hasta fines del período colonial 27.

A los bienes del mayorazgo (ver anexo 3), se unieron los de la dote de su esposa, 22000 pesos entre alhajas y bienes que le correspondieron a la muerte de sus padres, dote de gran consideración en el partido. Además, durante el matrimonio, los bienes y el capital líquido se incrementaron (ver anexo 4). Todo esto le convirtió en un hombre acaudalado. Su solvencia económica le permitió, por ejemplo, otorgar fianzas por dos empleos de la administración hacendística del puerto de Paita, las cuales no solían tener precisamente un carácter altruista por parte de quien era uno de los principales propietarios y, como veremos, comerciantes del partido28. Ello podía ser uno de los medios para condicionar bajo su persona a las autoridades clave, las que daban el visto bueno a todas las transacciones que se realizaban desde este puerto, fundamental en el circuito de acopio y redistribución hacia los mercados locales y extra virreinales. Finalmente, Francisco Javier obtuvo el marquesado de Salinas por decreto del 10 de julio del año 1820, por renuncia que hiciera a su favor su tío Gregorio Fernández de Paredes (AGN, 1820, Real Audiencia. Libro de tomas de razón de títulos). Por ello fue que recién en el año 1821 Francisco Javier y María de la Cruz aparecieron como nobles titulados en la documentación.

Con los marqueses de Salinas queda corroborado que el título nobiliario - ya de por sí importante- debía descansar sobre una fuerte base económica; la conjunción de ambos elementos garantizaba un prestigio personal y familiar que difícilmente podía cuestionarse, decaer o diluirse en el tiempo. Ello también garantizaba en el imaginario popular, igual que veíamos con Tomás, la idea de personas y familias poderosas, imponentes, asunto clave en medio de una mayoría poblacional que no gozaba de una holgada situación y cuya relación con estos «señores» era fundamentalmente de sujeción. Solo así se puede explicar que, en poco tiempo, Francisco Javier se haya posesionado de casi todo el valle del Chira y afirmada su presencia en las serranías piuranas; en ambos casos, gracias a sus

27 En una transacción en el año 1821, en la que Francisco Javier la pone de garantía por más de 5500 pesos, las autoridades dan su visto bueno afirmando: «De todas las propuestas sólo la de Francisco Fernández de Paredes está arreglada porque ofrece la determinada garantía de su hacienda nombrada Tangarará, capaz de responder por más considerables sumas...» (ARP, 1821, serie: Gobierno Político y Militar - Causas civiles. Leg. 2. Exp. 28).

28 En 1812 fue fiador por 2000 pesos de Manuel Gonzáles de Otoya, administrador de la estafeta del puerto de Paita, y, por la misma cantidad, de José Ruiz Muxica, administrador de rentas unidas de Paita. Se recurrió a Francisco Javier Fernández de Paredes como fiador, por muerte del anterior garante, Miguel Serafín del Castillo (ARP, 1812, serie: notarial. Notario: Antonio del Solar. Leg. 55. Prot. 10). 
haciendas y potreros 29 . En el fondo, todo ello tuvo mucho que ver con ese carácter altivo, frío, déspota que le venía por generaciones.

Para su definitivo establecimiento en Piura, Francisco Javier se sirvió de las dos haciendas que había heredado, Tangarará en la costa y Morropón en la sierra, a manera de compras de pequeñas tierras de los alrededores, y arriendos. Entre 1809 y 1815, Francisco Javier fue adquiriendo los trozos de orillas y montes colindantes a la hacienda Tangarará. Dos de las fronteras de la hacienda Tangarará pertenecían a terrenos de los hermanos Romualdo, Blas y Petrona Forero, «de condición mixtos», correspondientes al actual distrito de Marcavelica, en el valle del Chira; en total 317 varas de tierra que adquirió en 370 pesos. En el mismo año 1809, Mariano del Carmen Viera, indio de la doctrina de la Punta, vendió a Francisco Javier 7 cuadras 60 varas de largo de tierras de humedad con sus montes, también en Marcavelica, frontera sur con la hacienda Tangarará. En la misma jurisdicción se ubicaba la hacienda Pazul, perteneciente a María Echavarría, vecina de Tumbes; dicha posesión también le fue vendida a Francisco Javier en el año 1815 en 200 pesos. Al año siguiente, Justo Vital, Pedro Lázaro y María Gutiérrez hacen lo mismo con dos acciones de tierras de Marcavelica en 300 pesos (ARP, 1809, serie: notarial. Notario: Antonio del Solar. Leg. 52: fols. 238, 315 y 344; 1815, serie: notarial. Leg. 57: fol. 179v-182, fol. 298-309; 1816, serie: notarial. Leg. 58: fol. 229v-234v).

Con estas y otras adquisiciones, Francisco Fernández de Paredes obtuvo prácticamente el absoluto control de la zona del valle del Chira, logrando acrecentar la extensión de la hacienda a costa de los pequeños propietarios colindantes, indios o mestizos, que posiblemente, no tuvieron otro remedio que vender sus tierras, siendo algunos de ellos viejos deudores de Tomás30. Esto mismo aconteció, posiblemente, en el conflictivo año de 1821, cuando individuos de La Punta vendieron parte de sus tierras a Francisco Javier, ya en ese entonces marqués (ARP, 1821, serie: notarial. Notario: Manuel Rebolledo. Leg. 1: fol. 32). Las adquisiciones de tierras continuaron en la época republicana, y así en el año 1825, obtuvo el terreno que le faltaba poseer — en la parte norte de la hacienda de Tangarará- en 521 pesos (ARP, 1825, serie: notarial. Notario: Manuel Rebolledo. Leg. 5: fol. 21v). En estas compras se invertía parte del beneficio obtenido con el arriendo de tierras de la misma hacienda, sobre todo para potreros de ganado, una práctica frecuente entre los hacendados piuranos, y muy lucrativa.

Otra hacienda vinculada al mayorazgo de los Fernández de Paredes era Morropón, ubicada en el partido de Santa Ana en la sierra piurana, que correspondió primero a Manuel y luego a Gregorio Fernández de Paredes, tíos de Francisco. En 1814, Gregorio concedió la hacienda a su sobrino en arriendo por nueve años, a 2500 pesos anuales. A partir de ese momento, Francisco Javier tuvo también el control de un distrito importante de la serranía de Piura, caracterizado por la riqueza de ganado vacuno, sobre todo31. Evidencia de que esta hacienda serrana rendía bien, es el subarriendo que de ella hizo Francisco

${ }^{29}$ Se deduce que estos potreros eran muy extensos pues Francisco Javier afirma arrendárselos «con todos sus montes, chacras, bebederos, y demás que se comprende dentro de sus cercos» (ARP, 1814, serie: notarial. Notario: Antonio del Solar. Leg. 56: fol. 53-54).

30 En 1796, Andrés Moscol, Petrona Forero y Mariano del Carmen Viera habían obtenido un préstamo de 510 pesos de Tomás Fernández de Paredes, habiendo empeñado sus tierras, «... las tierras de Marcavelica, situadas en el río de La Chira». Los 510 pesos pudieron ser cancelados recién el 2 de junio de 1809, recuperando sus posesiones solo momentáneamente. Dicho esfuerzo los dejaría más que exhaustos, teniendo al mes siguiente que vender esas mismas tierras a Francisco Javier (ARP, 1809, serie: notarial. Notario: Antonio del Solar. Leg. 52: fol. 236v).

31 Los arriendos de la hacienda de Morropón fueron numerosos durante las dos primeras décadas del siglo XIX, reportándoles beneficios mucho más allá de los iniciales años del gobierno republicano. 
Javier, en 1823 y por nueve años, al regidor Antonio Palomino, en la cantidad de 3330 pesos anuales; un 33 \% superior al que él había convenido con su tío. Esta operación sugiere que los hacendados piuranos siguieron manejando muy buenas perspectivas económicas para el futuro, a pesar de la convulsa situación del país en esos años. Es muy probable por ello que esta región estuviese bastante al margen de la situación de general empobrecimiento de la capital virreinal y ciudades más importantes en el tiempo de las guerras de independencia. Lo que queda claro es que los medios que Francisco Javier empleó para que ambas haciendas le reportaran beneficios fueron determinantes en este particular momento de inestabilidad política.

Complementario al poder que le brindaban las haciendas, en el fortalecimiento de Francisco Javier en Piura tuvo mucho que ver su actividad mercantil. Se dedicó al comercio, aunque en menor medida que otros emblemáticos comerciantes de la región. Parte de sus transacciones las llevó a cabo en la ciudad de Lima32, otro tanto en Lambayeque, y también en Trujillo sirviéndose de las conexiones establecidas por su tío Tomás. No comerció directamente, sino, como la mayoría de los vecinos piuranos, a través de intermediarios33. Además, compró un bergantín nombrado Gran Poder de Dios —alias Jesús, María y José- a Guillermo Franco Caballero, vecino de la ciudad de Guayaquil, que puso en manos de otro comerciante, Ángel Castro, recorriendo varios puertos del Pacífico Sur, desde Coquimbo hasta Paita (ARP, 1812, serie: notarial. Notario: Antonio del Solar. Leg. 55: fol. 447). Muy pocos vecinos piuranos poseyeron una embarcación propia, sea para comerciar directamente o para darla en concesión, e indica tanto holgura económica como preocupación por diversificar las inversiones y asegurar la salida a los productos de sus tierras.

Estamos, por tanto, nuevamente frente a un hombre con mucho poder en el entorno, poder sin restricciones del que se sirvió en reiteradas oportunidades para incrementar sus beneficios económicos mediante la injusticia y la ilegalidad. El hacendado José de Lama, dueño de la hacienda Máncora, acusó a los Fernández de Paredes de haber incrementado sus tierras a lo largo del tiempo por posesión ilícita de pastos colindantes; al tener ya todo bajo su potestad, el objetivo era apropiarse de tierras de Máncora. La determinación de los linderos de las haciendas fue siempre un problema añadido, en tanto que eran establecidos por la vecindad con otros propietarios y no por un estudio topográfico exacto. Sin embargo, en este caso José de Lama acusa ser ésta una apropiación sistemática y muy meditada.

¿Qué papel le competía a Francisco Javier en todo esto? El más importante después de lo realizado por su tío Tomás: falsificación de documentos, presentación de testigos falsos, firma de autoridades indígenas que no sabían leer ni escribir pero que trabajaban para la familia, entre otras «... medidas rastreras fraguadas en el secreto de su gabinete, ejecutadas en alta noche, empleando dependientes mercenarios...» («Deslinde de Morropón», 1890: fol. 19). En esos propósitos, Francisco podía arremeter contra cualquier persona que se le pusiera delante, sea miembro de la élite y autoridad, como en el caso de José de Lama,

32 En un poder otorgado en 1809 a Santiago Cachoufeirio, comerciante limeño, Fernández de Paredes mencionaba los productos en torno a los cuales giraba su actividad comercial: «Para la venta de los efectos que le remitiese de esta ciudad [Piura]. Para que... compre cualesquiera esclavos por los precios en que se ajustare... Para que pida al crédito cualesquiera mercaderías de Castilla o de la tierra, y los demás efectos que le ordenare por mis instrucciones...» (ARP, 1809, serie: notarial. Notario: Antonio del Solar. Leg. 52: fol. 147-148v).

33 Francisco se sirve de un gran comerciante piurano, Pedro de León y Valdés, quien sí negociaba directamente con varios puertos. En el año 1810, León se hallaba próximo a viajar a Panamá; Francisco aprovechó esta ocasión para concederle un poder para negociar hasta por 8000 pesos, cantidad mediana en el conjunto de transacciones de los pudientes comerciantes provincianos, pero nada desdeñable (ARP, 1810, serie: notarial. Notario: Antonio del Solar. Leg. 53: fol. 3-3v). 
o sean también habitantes de esos poblados objeto de su interés. Cuando Francisco se propuso posesionarse de Potrerillo y de las quebradas que nacen de Cerro Prieto:

«Empezó por cobrarles arriendos exigiéndoles a mano armada, y amedrentándolos con partidas de negros, que estaban prontos a llevarlos presos a los calabozos de Tangarará, a derribar las casas, y a apoderarse de los ganados. Estas tropelías eran tan frecuentes que muchos de los arrendatarios abandonaron estos sitios y se fueron a buscar pastos para sus ganados en los puntos más elevados de la cordillera, huyendo de los vándalos que los saqueaban y perseguían. Otros dejaron enteramente la cría de ganados y se dedicaron al cultivo de las tierras, donde encontraban, aunque escasa, una segura y tranquila subsistencia» («Deslinde de Morropón», 1890: 19).

Similares acciones son recogidas por César Espinoza34 y las mismas acusaciones fueron realizadas, como veremos más adelante, por los milicianos dependientes de Francisco Javier, hecho que corrobora el carácter despótico consuetudinario de los miembros de este clan familiar, quienes en el intento de apropiarse de más y más tierras productivas, no reparaban en los maltratos y excesos de todo tipo que cometían con regular frecuencia 35 . El otro ángulo es el temor con que indios, mixtos y demás grupos les miraban, especialmente a Francisco Javier. Si bien, como se verá, consta el intento del común de los indios de Tumbes por defender sus tierras frente al marqués, ello constituyó una excepción, en tanto que no existen otros reclamos de esta naturaleza ante el superior gobierno o ante el Estado peruano. Con todos estos mecanismos, legales e ilegales, y seguro de la influencia y recelo que su solo nombre infundía en el vecindario y entre los más desprotegidos, Francisco Javier llegó al final de la Colonia como el hombre más poderoso del partido piurano.

\section{2. Francisco Fernández de Paredes ante la independencia de Piura}

El último marqués de Salinas es definido por Reynaldo Moya como un realista convencido (Moya Espinosa, 1981-1984, IV: n. 658) y, en efecto, la documentación confirma esta catalogación. No es de extrañar que lo fuese, en tanto que descendiente de una élite, la capitalina, muy apegada al régimen monárquico por generaciones, y en tanto que, como todos los miembros de este estamento, era consciente que todas sus prerrogativas y sus beneficios los había conseguido amparado por el único sistema de gobierno que, hasta entonces, había preservado el apellido; el solo hecho de contar con un título nobiliario le hacía dependiente de la metrópoli que «graciosamente» se lo había concedido. De esta manera, su monarquismo fue manifiesto en su desempeño en las milicias, en su participación en campañas, así como en sus voluntarios donativos a la causa real en los distintos momentos en que fue necesario apoyar al Virrey.

Formó parte del cabildo de Piura como alcalde de segunda nominación en 180836. El año siguiente se mantuvo en este cargo, pero se hallaba fuera de esta institución cuando, en 1810, llegó la invitación de la Junta de Regencia para enviar diputado a Cortes, y cuando se constituyó

34 «Amotape ubicado casi al final del valle del Chira, es incendiado por el Marqués de Salinas en compañía de bandas armadas» (citado por Hocquenguem, 1998: 298). Estas acciones se sucedieron durante las guerras por la independencia por el enfrentamiento entre los hacendados piuranos y sus colonos (Espinoza, s.f.: 31).

35 «Continuaron las usurpaciones en todos sentidos, y muerto el Dr. D. Gaspar Vásquez de Velasco, su suegra Da. María de la Cruz Carrasco, o mejor dicho su apoderado D. Carlos Valle, concibió todavía un plan más atrevido para legalizar todas esas usurpaciones, y hacer otras nuevas, plan consistente en medios experimentados, y en las ventajas que proporciona un pleito entre personas desvalidas y miserables, y los grandes potentados» («Deslinde de Morropón», 1890: fol. 24).

36 Alejandro Reyes Flores afirma que Francisco Javier Fernández de Paredes fue subdelegado del partido de Piura en el año 1808 (Reyes Flores, 1999: 61). Pero este dato no parece acertado: ni su hoja de méritos 
el primer cabildo constitucional. De este segundo momento solo consta su participación en el cabildo abierto que dio lugar a la elaboración del padrón de electores de la ciudad, y su insistencia en el derecho que tenían los indios a participar también en estas votaciones.

En 1811 recibió el mando del Escuadrón de Dragones de las milicias provinciales disciplinadas de Amotape y compañías agregadas de La Chira y Tumbes. En 1814 llegó a ser, por seis meses, comandante de todas las milicias del partido de Piura (AGN, 1817, serie: Real Hacienda - Ejército. Leg. 6). En el año 1815 volvió a ser elegido alcalde ordinario, esta vez de primera nominación; y desde entonces demostró especialmente su adhesión al régimen monárquico, con su aportación económica a la causa realista y acudiendo como comandante de las milicias a la defensa de Paita del ataque de Cochrane en abril de 1819.

Su actuación a favor de la causa real en esta circunstancia concreta está fuera de duda, siendo uno de los más diligentes en la dirección de sus tropas para dar seguridad al vecindario. El comandante de las tropas de Piura José Casariego, se expresaba de él de la manera siguiente:

«El comandante de Amotape con una velocidad sola de su espíritu, reclutó en 24 horas gente suficiente de la mejor caballería. Mandó a este cuartel los soldados dispersos de la guarnición de Paita con algunos fusiles, y recibí por éste noticias de la pérdida del puerto con sus circunstancias...» (Elías, 1971-1972: 70-71).

La seguridad de la ciudad de Piura fue el objetivo de fondo del contraataque que se organizó. Una de las acciones de Fernández de Paredes fue precisamente devolverles la tranquilidad. Con la gente que había conseguido reclutar

«... se presentó el comandante Paredes en marcha precipitada en los ejidos de esta ciudad, llenándola de gozo y desvaneciendo los temores en que estaba sumergida».

El informe de Casariego culmina con un llamado al reconocimiento de la actividad desplegada por Francisco Javier:

«Por ahora estimula a todos por su aplicación al real servicio el infatigable comandante del escuadrón de Amotape D. Francisco Javier Fernández de Paredes...» (Elías, 1971-1972: 70, 72).

Otra evidencia de esa simpatía por el orden existente, y del interés por conseguir mayor ennoblecimiento y presencia en la esfera de control provincial o, quizás, capitalina, en el año 1818 Francisco Javier concedió un poder de representación a Galo Rodríguez, agente de negocios de Indias en la corte de Madrid, para que se presentase ante el rey o sus ministros y suplicara las consabidas mercedes de gracia y justicia (AVV, Piura, 14 de octubre de 1818). Y en 1820 — tras su participación en el rechazo de los insurgentes del puerto de Paita - se le concedió grado de Coronel de Milicias, uno de los rangos más apetecidos por la élite patricia criolla (BN, 1828, D10929). Todo esto muestra su completo acomodo en el sistema existente.

Pero su actitud hacia el sistema monárquico se manifestó con más claridad que nunca en el crucial cabildo abierto del 4 de enero de 1821, en el que se proclamó la independencia del partido de Piura, en hechos aún polémicos (Hernández García, 2005b: 360-383). Cuando ya se había determinado proclamar la independencia por San Martín, se aproximaron a la mesa directiva un barbero de apellido Bauza «del Sr. Paredes» y un platero nombrado Francisco La Madrid «en estado de embriaguez en que parece se les había llevado 
calculadamente», quienes dijeron en alta voz que ellos morirían por su Rey. Ambos, según relata José María de Arellano, habían sido llevados en ese estado por Francisco Javier, pues, éste intentó aprovechar la situación suscitada para argumentar que el pueblo estaba dividido e intentar detener la ceremonia. Son muy elocuentes sus palabras en ese momento, cuando, levantando el brazo para enseñar los galones de coronel de milicias, dijo: «mi investidura acredita mi decisión»37.

No obstante esta intervención, la ceremonia de proclamación continuó, y el cabildo abierto procedió a nombrar a las nuevas autoridades. A partir de este momento, las fuentes silencian cualquier alusión al comportamiento posterior del marqués en relación con la derrotada causa realista. Este silencio dificulta la comprensión del personaje, al que vemos, casi inmediatamente después, del lado republicano; tanto, que parece incluso darse prisa por demostrar su cambio de bando. Este repentino traspaso de una causa a otra no ha sido suficientemente explicado o analizado en la bibliografía sobre el tema38. Por esa ausencia de datos en los documentos, por sus «patrióticas» acciones inmediatamente posteriores, así como por la desconfianza que su adhesión inspiraba a muchos, es muy probable que en ese cambio haya primado un interesado acomodo a las nuevas circunstancias, hecho bastante común entre los miembros de la élite privilegiada de distintas partes de América; el marqués no sería ninguna excepción. Sin embargo, no convenció nunca del todo.

Como comandante del contingente militar en el pueblo de La Huaca, y aprovechando su ascendiente, logró que Manuel Diéguez, en nombre de la Junta Gubernativa establecida en Piura, lo nombrase su delegado para establecer un cabildo patriota en ese pueblo. Así que el 1 de abril de 1821, a escasos tres meses de haberse manifestado contra la independencia piurana, el marqués de Salinas juramentó al pueblo reunido en La Huaca «en nombre de Dios y de la Patria». Él fue el primero en firmar el acta. A partir de este momento, fue tomado en cuenta en los acontecimientos de la Piura independiente, pues se consideró que había hecho «méritos». Sin embargo, y como era lógico, permaneció la desconfianza hacia él, como se refleja en una de las cartas que José de San Martín envió al marqués de Torre Tagle:

«Todas las propuestas de oficiales que U. me ha hecho, han sido despachadas, y sólo he suspendido la del grado de Brigadier que pide el Marqués de Salinas, así porque no creo conveniente prodigar los grados superiores, como porque concibo que U. no se inclina a apoyar fuertemente su solicitud, según el tenor de su oficio; dígame U. sin embargo, con la franqueza que expone, lo que desea a este respecto, y se hará lo que guste» 39 .

Adviértase también que había solicitado el ascenso a brigadier, en atención al servicio que había prestado a la «patria», buscando reafirmar así su opción por el lado independentista.

37 «... en medio de este solemne acontecimiento, fausto y memorable, sólo se hizo notar el Sr. marqués de Salinas... por su imprudencia e impopularidad, pues fue el único que en esos momentos de crisis, abusando del carácter suave y moderado de un pueblo pacífico, se opuso a su voluntad soberana que acababa de asumir, arguyendo que el pueblo estaba dividido por lo que dijeron sus dependientes, y levantando el brazo para enseñar los galones de tal y su bastón dijo: Mi investidura acredita mi decisión...» (Arellano, 1958: 14-15) (La cursiva es nuestra).

38 Reynaldo Moya, por ejemplo, trata de explicarlo del modo siguiente: «Es posible que tuviera una pronta percepción de la situación, y que viera que la causa realista estaba ya completamente perdida, o quizá también por el llamado de la tierra y el ejemplo de tanto piurano - ya sea del pueblo como de los grupos aristocráticos - que con gran fervor habían volcado sus entusiasmos y sus afanes por la causa de la independencia. Lo cierto es que no pasó mucho tiempo, y el empingorotado Marqués de Salinas se sumó al bando de los patriotas con tanta vehemencia y voluntad como antes había servido al Rey» (Moya Espinosa, 1983: n. 674).

39 Carta de San Martín a Torre Tagle, Huaura, 26 de marzo de 1821 (Ortíz de Zevallos, 1989: 66). 
El momento así lo requería, pues la política de persecución contra los realistas se inició en el norte virreinal antes - incluso- de la llegada de Bernardo de Monteagudo a la esfera política peruana, destituyendo a los partidarios de la monarquía 40 , denegando los pases para que los peninsulares abandonasen el partido o secuestrando arbitrariamente algunos bienes ${ }^{41}$.

En definitiva, Francisco Javier tuvo que adaptarse al nuevo estado de cosas. Dadas las circunstancias, y considerando la posición económica y social de la familia, más se ganaría estando del lado de los ahora victoriosos «patriotas»: era la única forma de conservar los privilegios adquiridos con tanto esfuerzo. De momento, su cambio de actitud le posibilitó mantener sus posesiones intactas, así como sus giros mercantiles. En el mismo año de 1821 nombró como apoderado de sus cobranzas y pleitos a su tío Gregorio Fernández de Paredes, residente en Lima (ARP, 1821, serie: notarial. Notario: Manuel Rebolledo. Leg. 1. Prot. 5). El gobierno local confió en él hasta el punto que, en el año 1827, el prefecto de La Libertad lo propuso en primer lugar en la terna para elegir ecónomo del convento betlemítico de Piura; propuesta que fue aceptada por el gobierno de Lima42.

Hay que recordar dos cosas. Primero, que el convento de los betlemitas subsistió a la supresión de la cual fueron objeto los conventos de regulares en el año 1826, cuando en Piura fueron suprimidos los de San Francisco y La Merced, así como en Paita también el de los mercedarios (AGN, 1827, RJ. Leg. 146: fol. 1); y en segundo lugar, que el ecónomo en este contexto era la persona encargada de administrar los bienes del convento, así como de elaborar una razón prolija de sus rentas en representación del Estado republicano. Definitivamente, Francisco Javier era para el gobierno limeño una persona en quien cabía confiar, a pesar de algunas graves acusaciones que, ya para ese entonces, se le habían hecho llegar.

Si bien el mejor modo de mantener o incluso acrecentar su posición en ese momento era la milicia, el marqués de Salinas tuvo otra alternativa brindada por su caudal económico: volver a ser fiador de algún vecino piurano «a favor de la Real Hacienda» [sic], pero esta vez por nombramiento del nuevo gobierno, representado por el marqués de Torre Tagle ${ }^{43}$ y, sobre todo, ser prestamista del nuevo Estado republicano. En el año 1821 concedió 500 pesos en calidad de empréstito al Protectorado. Dado que el Estado no tenía recursos, el marqués de Salinas se hizo devolver este empréstito con el dinero de la suscripción obligatoria que las distintas provincias independientes tenían que pagar a Lima; en concreto, de la suscripción de La Chira y Tumbes, posesiones del marqués y dinero recaudado por él. De esa manera recuperó lo prestado al año siguiente, y nadie le pudo negar el haber contribuido a la causa de la libertad44.

40 José María de León, por ejemplo, fue nombrado por Torre Tagle administrador de la aduana de Piura por la deposición de Manuel Tirado «por antipatriota», en febrero de 1821 (AGN, 1822, OL. 30-29: fol. 5).

41 José María Lequerica envió una acusación al Congreso Constituyente el 4 de enero de 1823 contra Félix Olazábal, «... que violentamente se apoderó de sus bienes en la ciudad de Piura...» (Pons Muzzo, 1971: 236).

42 La terna incluía a tres patricios piuranos importantes, y que en el año 1821 habían tenido una actuación política poco clara: Francisco Fernández de Paredes, Manuel Rejón (peninsular), y Miguel Gerónimo Seminario y Jaime (piurano), en ese orden respectivamente.

43 Por ejemplo, fue fiador de Jacinto Otoya en 500 pesos, por su cargo de Vista de la aduana de Paita, en octubre de 1821 (ARP, 1821, serie: notarial. Notario: Manuel Rebolledo. Leg. 1. Prot. 5: fol. 123).

44 «Piura, 9 de febrero de 1822. Son data 500 pesos que la Junta de Arbitrios ha procedido a pagar al Sr. Vocal de ella, Marqués de Salinas, por el empréstito que hizo de igual cantidad en dos partidas de a 250 pesos... según consta en las sentadas en el Libro auxiliar del año de 1821 ... y esta devolución o pago se ha hecho del producto de la suscripción del río de La Chira y Tumbes, según así consta del recibo del prestamista, y remitido con oficio de esta fecha para la cancelación correspondiente a favor del Estado...» (BN, 1822, D8411). 
Es más, esa «contribución» le facilitó la compra al Estado de unas tierras en la provincia de Tumbes. Esas tierras — denominadas Los Corrales-, eran propiedad de la comunidad de indígenas del lugar; pero, como ocurrió con la mayor parte de los comunales indígenas, el nuevo Estado liberal las consideró «sobrantes» y procedió a subastarlas en junio de 1826. Los indios, a pesar de ser los verdaderos propietarios, acudieron a la subasta con su oferta y una justificación de su posesión desde la época virreinal. Ambas fueron desechadas y el resultado del remate fue favorable a Fernández de Paredes, que no solo consiguió las tierras, sino también la administración de los arrendamientos de las chacras y ganados de los colonos indios de Tumbes. El resultado de la subasta no se dio a conocer a los indios, quienes remitían en el mes de octubre su queja: «Hasta la fecha se ignora el resultado, y recelando este vecindario alguna sorpresa de privados interesados, se toma la libertad este cuerpo de dirigirse a V.E. en derechura...», pues lo que la municipalidad quiere es «... que estos moradores pobres trabajen tranquilos, separadamente, sin sufrir perjuicios y agravios de alguno o algunos de los propietarios prepotentes...». Estamos de nuevo ante los arbitrarios mecanismos con los que Francisco Javier se había hecho de cada vez mayores posesiones, con el visto bueno de las autoridades locales; el común de indios lo sabía o intuía, por ello recurrió a la justicia de la capital. Sin embargo, y a pesar de sus reclamaciones, el gobierno apoyó al marqués, ratificándole como dueño de estas tierras (ARP, 1826, serie: Gobierno Político y Militar - Causas civiles. Leg. 2. Exp. 28)45. La apuesta por «la patria» estaba dando sus frutos.

El 13 de abril del año 1822, el ministro de guerra, Tomás Guido, envió despachos ascendiendo o reconociendo grados militares a los oficiales del escuadrón de dragones de Amotape por haberse destacado como «patriotas». En aquella relación figuraban dos Fernández de Paredes: Francisco Javier, al que se nombró comandante con grado de coronel, y su primogénito Teodoro de los Santos, que recibió una capitanía (De la Barra, 1971: 67). La familia mantenía su poder en las milicias ahora republicanas.

Una de las acciones bélicas más importantes en las que participaron las milicias piuranas fue la batalla de Pichincha, en junio de 1822, por la que se liberó Quito. Bajo el nombre de «Batallón Piura», se congregaron tropas de distinto origen, inclusive chilenas, al mando general de Andrés de Santa Cruz. El «Batallón Piura» estuvo en el campo de batalla, pero permaneció en reserva durante la contienda (Denegri Luna, 1971: 374). A pesar de ello, tras el triunfo patriota, sus componentes fueron condecorados por el gobierno protectoral peruano, y entre ellos el marqués de Salinas, distinción que enlucía la lista de servicios a la causa libertadora del Perú (De la Barra, 1971: 80).

Su carrera en las milicias fue en continuo ascenso, consecuencia no solo de sus acciones a favor de la patria, sino también de todo el contexto caudillista en el que se desarrollaba la política peruana en esos años. Así, en 1823 Francisco Javier fue ascendido a Comandante Principal de los Cuerpos Cívicos de la provincia de Piura, lo que le convertía en la máxima autoridad militar de todo el partido piurano; tamaño poder no lo había obtenido en el sistema de gobierno anterior, así que representó un auténtico triunfo, el poder perfecto en un mundo en el que los altos mandos militares se habían convertido en los protagonistas de la historia nacional. Si bien esto supuso un paso importante en la reafirmación de su sitial en la República, del lado de quienes estarían bajo su liderazgo el tema despertó nuevos temores y antiguas animadversiones.

45 En dicha transacción, el propio Francisco Javier menciona: «Yo soy acreedor del Estado en cantidad considerable...» [se refiere a los 500 pesos], por lo que se le concede «...se le exonere del pago efectivo de los 1950 pesos que debe por resto de 3950 en que se le remataron [las tierras] según el expediente que acompaño». 
El nombramiento fue muy mal recibido por la oficialidad miliciana en Piura, que, en una representación al supremo gobierno en el año 1823, mostraba el resentimiento existente contra su persona y las más que serias dudas sobre su fidelidad a la República, sugiriendo incluso su conexión con las tropas realistas que, se temía, preparaban la reconquista de Piura desde el Ecuador:

«Los oficiales que suscriben... representan: que han visto con dolor la comisión que ha sido confiada al Marqués de Salinas, de comandante principal de los cuerpos cívicos de la provincia de Piura. El Marqués de Salinas, tan conocido en toda la provincia como odiado de todos sus habitantes, tiene dadas las mayores pruebas de su carácter díscolo, y no pocos indicios de enemigo de nuestra sagrada causa... Él arengó a los patriotas piuranos el día de su decisión, mostrando su divisa de coronel del gobierno real, y añadiendo que su investidura no desdecía de sus sentimientos, que las tropas realistas que se hallaban en Cuenca, harían en breve sucumbir la provincia, y finalmente empleó todos los medios de la seducción a fin de alucinar a los moradores de aquel suelo que hoy se miran cubiertos de gloria»46.

Es muy probable que, efectivamente, las tropas realistas tuvieran pensado bajar hacia Tumbes, Piura, Lambayeque y Trujillo a poner en aprietos a los independentistas. Ya antes, entre 1819 y 1820, contingentes de milicias realistas vinieron por Piura hacia Trujillo o hacia Lima, como por ejemplo, el batallón «Numancia» que luego pasó a formar parte de las filas de San Martín. Cuenca y Loja fueron puntos geográficos que preocuparon tanto al marqués de Torre Tagle como a San Martín, cuando no se había aún proclamado la independencia de Lima47.

Los militares piuranos reforzaban su rechazo al nombramiento de Fernández de Paredes recordando al gobierno que Francisco Javier, antes que nada, era el conocido hacendado déspota y arbitrario, para lo cual había servido su condición de marqués:

«El Sr. Gral. de División Andrés de Santa Cruz, fue un fidedigno testigo, en el tiempo que mandó en la enunciada provincia, del procedimiento tiránico con que trataba aquél [Fernández de Paredes] a sus arrendatarios o colonos, hasta el extremo de quemarles sus casas y despojarles de sus chacras en el tiempo oportuno de su cosecha; valiéndose para este efecto de subir a un excesivo precio los arriendos, y de otros motivos ilícitos hasta obligarlos a abandonar su trabajo y perder sus frutos. Si este comportamiento es una de las mejores obras del Marqués de Salinas, y para tantas injusticias le bastó ser título y hacendado, permítasenos juzgar que, con el mando que por comisión administra, serán aquellas infinitamente más horrendas y de guarismo incalculable»48.

46 Representación de los militares piuranos que, como beneméritos oficiales del Ejército del Perú, elevaron al Supremo Gobierno el año 1823, oponiéndose al nombramiento de D. Francisco Javier Fernández de Paredes, Coronel de Ejército, ex-marqués de Salinas, de Comandante Principal de los cuerpos cívicos de aquella provincia (Imprenta Republicana, 1827, Lima: fol. 1) (La cursiva es nuestra).

47 Borrador de la respuesta de Torre Tagle a carta de San Martín, 11 de marzo de 1821: «... sería muy conveniente que $U$. me mandase de 200 a 300 veteranos buenos... éstos unidos a las milicias de aquí y a las de otros puntos, harían una división respetable... los transportaría a Piura al primer aviso de Olazábal, y con aquel batallón, sería sin duda derrotada cualquiera expedición que de Cuenca invadiese por aquella parte». A San Martín también le preocupa el norte, y escribe a Torre Tagle los siguiente: «De oficio digo a U. lo que ocurre de más urgencia sobre el riesgo a que podía verse expuesto el partido de Piura, si se verifican las noticias a que aluden las cartas de Loja que me remite en su última comunicación...». Carta de San Martín a Torre Tagle, Huaura, 26 de marzo de 1821 (Ortiz de Zevallos, 1989: 62, 66).

48 Representación de los militares piuranos que, como beneméritos oficiales del Ejército del Perú, elevaron al Supremo Gobierno el año 1823, oponiéndose al nombramiento de D. Francisco Javier Fernández de 
Pese a todo el temor, rechazo y odio que suscitaba entre sus milicianos por la crueldad en su trato, el gobierno no revocó el nombramiento; más aun, al final de sus días figuraba como Coronel del Ejército Peruano. En esta decisión importaba mucho al Ejecutivo la retribución - monetaria o con ascensos militares - a aquellos vecinos que habían apostado por la patria; era un modo de compensación y, sobre todo, de asegurarse sus recientes fidelidades. Fue una situación que se dio a lo largo de toda la República, pero que al mismo tiempo volvió intocables a los patricios locales, y mucho más poderosos a quienes lo venían siendo por generaciones, estableciendo con ello la base de la red de clientelaje que se consolidó durante todo el siglo XIX49.

En la inestable década de 1820, Francisco Javier supo reforzar su posición, además, con la participación activa en la política republicana. Representó al departamento de Trujillo en el Primer Congreso Constituyente del Perú del año 1822 junto a otros importantes vecinos piuranos, como Tomás Diéguez — trujillano y vicario eclesiástico en Piura- y Manuel José de Arrunátegui —presbítero piurano- - Ejerció como diputado desde el 8 de noviembre de 1822 hasta el 24 de mayo de 1823, cuando pidió dos meses de licencia para organizar un cuerpo de ejército que le había solicitado directamente el presidente Riva Agüero. Luego de esa licencia, Fernández de Paredes no volvió a sus funciones legislativas50. Los acontecimientos políticos y sus labores de hacendado le detuvieron en Piura, quedándose aquí hasta el momento de su muerte, ocurrida en su hacienda Tangarará el 18 de junio de 1839 (ARP, 1839, serie: notarial. Notario: Manuel de la Vega. Leg. 138: fol. 253)51.

A su ascenso en la milicia, su participación directa en la política piurana y en el nuevo Estado peruano recién constituido, la ascendencia que tenía sobre el resto de sus convecinos, que le permitió incluso superar las graves acusaciones que le hicieron y salir elegido en las votaciones de 1822, y a su poder económico, se sumó la ratificación del título de marqués de Salinas por parte de Torre Tagle en 1822, aunque al año siguiente fueron suprimidos todos los títulos de Castilla. Sin embargo, pensamos, ya para ese entonces no necesitaba de ningún título para continuar siendo «el marqués», pues se le siguió nombrando así por la vecindad y por el pueblo. En ello tuvo mucho que ver la tradición nobiliaria con que siempre miraron a los marqueses de Salinas en Piura, y con la nobleza que Fernández de Paredes se preocupó en mantener como otro claro referente de distinción y de poder.

\section{3. «Nobles» a pesar de la República}

A fines de la Colonia, Francisco Javier reunía el poder económico, fruto de una extensa red de transacciones mercantiles y operaciones de todo tipo que tuvieron como centro la posesión de la tierra, y el comercio en segundo lugar; el ascendiente social, otorgado no solo por el título nobiliario que le vino al final de una época, sino también por la familia de la cual descendía, apellidos de trascendencia en las esferas cultas de la capital; el poder militar, al formar parte de la plana mayor de las milicias disciplinadas de Piura y Amotape;

Paredes, coronel de Ejército, ex-marqués de Salinas, de Comandante Principal de los cuerpos cívicos de aquella provincia (Imprenta Republicana, 1827, Lima: fol. 1v).

49 Los caudillos locales constituyeron la base de ese entramado de clientelas que las guerras por la independencia y el militarismo empezaron a construir (Lynch, 1992: 498). Para el caso peruano, revisar el clásico estudio de Carmen Mc. Evoy (Mc Evoy, 1997).

50 Por estos cinco meses y medio, aproximadamente, el Estado le otorgó la dieta de 1980 pesos el año 1825 (Pons Muzzo, 1971: 452-453).

51 Sus restos reposan en el mausoleo de la familia, en el cementerio «San Teodoro» de la ciudad de Piura, que construyó en homenaje a su hijo Teodoro. 
y el poder político, manifestado en su pertenencia al ayuntamiento. Así construyó la base de un poder que el nuevo régimen republicano no pudo destruir. Al contrario, llegado el momento supo hacerlo efectivo para reforzar su posición y la de su familia en un entorno político y social solo aparentemente contrario a aquel en el que se había formado.

La familia de los marqueses de Salinas en Piura representó la lucha constante por la permanencia en el estamento de privilegio que les tocó en suerte. Francisco Javier y María de la Cruz Carrasco y Carrión tuvieron únicamente dos hijos, Teodoro de los Santos y Jacinta. El primero nació en Piura el 8 de noviembre de 1813 y fue bautizado en Catacaos el 17 de abril de 1814. Pero enfermó del pulmón y murió repentinamente en Frías, serranías de Piura, el año 1834, sin dejar descendencia (Trazegnies, 1945: 23).

Su deceso afligió profundamente a sus padres al ser el primogénito y el único hijo varón. Este pesar ha sido motivo de alguna tradición piurana que intenta recrear la angustia de Francisco por la pérdida de su hijo52. Lo real fue que, para honrar su memoria y ganarle el cielo, su padre construyó el primer cementerio público de Piura, al que pusieron por nombre «San Teodoro», inaugurado en 183853. En dicho cementerio reposan los restos de toda la familia Fernández de Paredes y de otros miembros de la élite, inclusive de los que murieron durante las guerras por la independencia, hasta las primeras décadas del siglo XX54.

Fallecido Teodoro, le sucedió en la herencia su hermana Jacinta, quien continuó con la tradición nobiliaria de la familia al casarse en primeras nupcias con Gaspar Vásquez de Velasco, limeño y último conde de Las Lagunas, en el año 1839, año también de la muerte de Francisco Javier, su padre55. Gaspar fue el hijo legítimo de José Juan Vásquez de Velasco y Ontañón, cuarto conde de Las Lagunas, y Mariana de la Puente y Carrillo de Albornoz, hija de Gaspar de la Puente e Ibáñez de Segovia, contador mayor del juzgado de bienes de difuntos (Trazegnies, 1945: 17)56, y de Lucía Carrillo de Albornoz y Bravo de Lagunas, descendiente del conde de Montemar (Rizo-Patrón, 2002: 156-157). Jacinta y Gaspar tuvieron dos hijos, Teodoro Miguel y María.

Por lo que parece en este caso, a pesar de ser Gaspar Vásquez de Velasco aquél sobre quien recayó el mayorazgo de sus titulados padres, no aportó caudal a dicho matrimonio, pues Jacinta solo menciona en su testamento como bienes suyos los correspondientes al mayorazgo de los Fernández de Paredes. Ello puede explicarse por el hecho que, para

52 Federico Helguero Seminario da cuenta de la tristeza del marqués en una de sus tradiciones: «Tan profundamente afectó esta desgracia al Marqués de Salinas que, desde entonces, no levantó cabeza, viéndosele siempre ensimismado y melancólico. Pasaba sus horas muertas en su casona de Tangarará... Cierto día, alarmado el mayordomo de la hacienda, Joaquín Escobar, por la tardanza del Marqués en salir de su despacho, penetró a él, y sorprendió a D. Francisco Javier acodado en una mesa, en actitud meditativa, ante larga pila de relucientes monedas. Joaquín Escobar... se atrevió a interrumpirlo. -Señor Marqués — le dijo quedamente- qué hace Uste? Por toda respuesta, el Marqués, sin cambiar de actitud replicó: -Todo esto le faltaba gastar a mi hijo...» (Helguero Seminario, 1974: 41-42).

53 «San Teodoro» fue el tercer cementerio que tuvo la ciudad. El primero quedaba en el ala izquierda de la Iglesia Matriz; el segundo, en las denominadas Pampas de Morón, al oeste de la ciudad, en ese entonces muy lejos del centro de Piura, inaugurado en el año 1814 por petición expresa de las Cortes de Cádiz.

54 Si bien el cementerio «San Teodoro» corre a cargo de la Beneficencia Pública de Piura, el mausoleo central sigue en poder de los descendientes de los marqueses de Salinas, ahora los Arrese Vásquez de Velasco, residentes en Lima.

55 En una publicación titulada «Gasparito en miniatura», del año 1846, se consignan algunas acusaciones contra Gaspar, entre las que se cuenta: «haber ocasionado la muerte del finado señor su suegro suministrándole un tósigo» (ARP, 1846, serie: Juzgado de Primera Instancia - Causas Administrativas. Leg. 284. Exp. 6112: fol. 1). La acusación no llegó a demostrarse.

56 El condado de Las Lagunas le fue concedido el 23 de noviembre de 1714 a D. Nicolás Ontañón Lastra (Izcue, 1929: 35). 
el año 1839, muchas de las fortunas limeñas habían visto mermado su capital a raíz de los acontecimientos inmediatos y posteriores a la consecución de la independencia; este matrimonio, entonces, bien pudo significar apoyo económico para la familia del esposo a cambio de añadir lustre nobiliario a la casa de Francisco Javier.

Los últimos intentos por mantener la pureza social del linaje se advierten en el segundo matrimonio de Jacinta. Gaspar Vásquez de Velasco murió en Tangarará el 21 de diciembre de 1847; al año siguiente, Jacinta contrajo nuevas nupcias con Pedro Arrese y Sañudo, otro miembro de la élite limeña ${ }^{57}$. Era hijo de Francisco de Arrese y Layseca, caballero de las órdenes de Santiago y Carlos III, que fue regidor de Lima y diputado a Cortes, y de Manuela Layseca, «fundadores estos últimos de la familia Arrese en el Perú» (Trazegnies, 1945: 19). Los hijos de este matrimonio fueron Francisco, Teodomiro, Clotilde, Pedro Enrique y Emilia Eugenia Arrese Fernández de Paredes (ARP, 1855, serie: notarial. Notario: Manuel Rebolledo. Prot. 91: fol. 132).

Aunque Jacinta seguía siendo la parte más acaudalada, Pedro Arrese consiguió incrementar los bienes de su esposa. Para el año 1856, la tasación de bienes de Jacinta ascendió a 128551 pesos (ARP, 1856, serie: notarial. Expedientes protocolizados. Notario: Manuel Rebolledo. Leg. 4)58, cantidad de gran proporción en la segunda mitad de esa centuria en la ciudad de Piura, aunque, si la comparamos con la capital, no tanto, teniendo en cuenta que se vive entonces en plena «fiebre del guano».

Las ramificaciones de esta familia van mucho más allá de nuestro ámbito cronológico de estudio. Obviamente como apellido, los Fernández de Paredes perdieron presencia prácticamente con Jacinta. Lo interesante aquí es advertir cómo se intenta mantener la prestancia social heredada en primer lugar, puesto que la ascendencia de los esposos de Jacinta fue — prácticamente- lo más solvente que estos pudieron otorgar a los Fernández de Paredes.

\section{A MANERA DE CONCLUSIÓN}

Al comienzo del artículo afirmábamos que la trayectoria del marqués de Salinas era ilustrativa de la actuación de la élite piurana en su conjunto durante las guerras por la independencia y la consolidación del nuevo sistema de gobierno. Efectivamente, hasta pocos días antes del momento en el que se tuvo que optar por el Rey o por la «patria» en aquel cabildo abierto del 4 de enero de 1821, la vecindad piurana en su conjunto se había caracterizado por su incondicional apoyo a la causa realista; los informes que el virrey Joaquín de la Pezuela incluye al respecto en su «Diario» son concluyentes, así como las noticias que la «Gaceta de Lima» difundió acerca del comportamiento de las milicias piuranas, encabezadas por la élite hacendada del lugar (Hernández García, 2005b: 361399). Definitivamente, el momento del quiebre lo pensaron bastante lejano, e inclusive, poco probable. Llegado el momento, sorprende la rapidez de ese cambio de bando, hecho que en Lima, por ejemplo, tardó muchos días más59. Y fue precisamente esa celeridad

$57 \mathrm{Al}$ casarse por segunda vez, a Jacinta se le quitó la tutela de sus dos primeros hijos, pasando estos al cuidado de María de la Cruz Carrasco y Carrión, viuda del marqués de Salinas y abuela de estos niños (AVV, Poder a D. Juan Bautista de Llano, vecino de Madrid, Piura, 7 de julio de 1853).

58 Aunque Jacinta hable de incremento de bienes, en realidad lo más importante que adquirió fue el sitio nombrado «Morroponsito», colindante con la hacienda Morropón heredada de Francisco Javier. Y al contrario, tenía varias capellanías que cumplir.

59 Entre el pedido del cabildo de Lima del ingreso de las tropas patriotas para restablecer el orden en la ciudad y la proclamación de la independencia en las plazas centrales y luego en las instituciones públicas más relevantes, pasaron tres semanas. 
la que la documentación recoge en la figura del marqués que, parafraseándolo, acreditó su decisión por el Rey con su investidura, pero que semanas más tarde sus supuestas convicciones se mostraron por completo distantes de aquella intempestiva intervención.

Francisco Javier Fernández de Paredes, con su hábil transformación de realista furibundo en ejemplar servidor de la nueva patria republicana, es un modelo casi perfecto del comportamiento de toda una clase social, la élite peruana en su conjunto, en una época de crisis $y$, en especial, de las estrategias que algunos de los patricios piuranos utilizaron para mantener su condición de élite en el nuevo entorno político.

Francisco Javier buscó maneras de reacomodarse a la nueva estructura, hecho que, si bien refleja una actitud más o menos generalizada, en su caso particular fue mucho más elocuente y específica, en tanto que no se trataba de cualquier vecino, sino de aquél que se hallaba a la cabeza de una estratificada sociedad local, en la que su tradición nobiliaria le elevaba, distanciaba y preservaba. Definitivamente, este ascendiente fue una de las maneras de no perder prestigio, lo que se demuestra en el primer matrimonio de su hija Jacinta, enlace en el que, siguiendo la costumbre de la época, él tuvo mucho que ver.

Para ese entonces, los títulos nobiliarios habían sido derogados; sin embargo, su constante alusión a que eran «ex marqueses de Salinas», «hijos de los marqueses de Salinas», «último conde de Las Lagunas», es claramente significativa de la fortaleza de la herencia hispánica y la debilidad de su conciencia republicana, así como del interés en distinguirse de los demás. De esta manera, los Fernández de Paredes, por sus vínculos matrimoniales y su adaptabilidad al nuevo estado de cosas, pasado el año 1821, continuaron luciendo la superioridad social en una provincia y en un momento en el que eran los únicos que representaban la conexión directa con el antiguo régimen.

Francisco Javier es un personaje que impone mucho por su influencia dentro y fuera del partido piurano; una persona que ha heredado una cuota de poder impresionante y que la acrecentó con su matrimonio, sus transacciones mercantiles y con la adquisición paulatina de grandes o pequeñas extensiones territoriales que rodeaban sus haciendas. Ese poder económico fue perfectamente utilizado cuando quiso demostrar adhesión y apoyo a la causa patriota, tan necesitada siempre de monetario.

El último marqués de Salinas en la Piura independiente, no obstante las reticencias que su persona inspiraba en el marqués de Torre Tagle y en las milicias piuranas de 1823, se mantuvo en su privilegiado estatus social, económico, militar y político. La independencia terminó por reafirmar su supremacía.

\section{Referencias citadas}

\section{Fuentes primarias}

\section{Archivo General de Indias (AGI)}

1804 Títulos de Castilla, 8

1811 Lima, 741, n. 91

1811 Lima, 741, n. 91: fol. 2-12

1815 Lima, 749 


\section{Archivo General de la Nación (AGN)}

1762 Serie: Notarial. Notario: Agustín Gerónimo de Portalanza. Prot. 871: fol. 30

1765 Serie: Notarial. Notario: Felipe José Jaraba. Prot. 554: fol. 14

1765 Serie: Notarial. Notario: Felipe José Jaraba. Prot. 554: fol. 15

1766 Serie: Notarial. Notario: Valentín Torres Preciado. Prot. 1067: fol. 500v

1783 Serie: Notarial. Notario: Julián de Cubillas. Prot. 581: fol. 438v

1783 Serie: Notarial. Notario: Julián de Cubillas. Prot. 581

1803 Superior Gobierno. Leg. 45. Cuad. 603

1803 Serie: Notarial. Notario: Gervasio de Figueroa. Prot. 244: fol. 65

1803 Serie: Notarial. Notario: Gervasio de Figueroa. Prot. 244: fol. 66

1803 Serie: Notarial. Notario: Morel de la Prada. Prot. 437

1814 Serie: Notarial. Notario: Ignacio Ayllón Salazar. Prot. 22

1814 Serie: Notarial. Notario: Ignacio Ayllón Salazar. Prot. 22: fol. 1871

1817 Serie: Real Hacienda - Ejército. Leg. 6

1820 Real Audiencia. Libro de tomas de razón de títulos

1822 OL. 30-29: fol. 5

1827 RJ. Leg. 146: fol. 1

1847 Serie: Notarial. Notario: Juan Cosío. Prot. 160

\section{Archivo General de Simancas (AGS)}

1797 Secretaría de Guerra. Leg. 7134. Exp. 109

1797 Secretaría de Guerra. Leg. 7134. Exp. 109: fol. 2v

1797 Secretaría de Guerra. Leg. 7134. Exp. 109: fol. 7v-12v

\section{Archivo Histórico Nacional de Madrid (AHN)}

1789 Órdenes Militares: Expedientillos, n. 8506

\section{Archivo Regional de Piura (ARP)}

1789 Serie: Notarial. Notario: José Miguel Zavala y Castilla. Prot. 5. Leg. 54: fol. 125

1797 Serie: Intendencia - Causas Criminales. Leg. 57. Exp. 1072: fol. 87

1797 Serie: Intendencia - Causas Criminales. Leg. 57. Exp. 1072: fol. 90

1797 Serie: Intendencia - Causas Criminales. Leg. 57. Exp. 1072: fol. 92

1802 Serie: Notarial. Notario: Antonio del Solar. Leg. 113

1806 Serie: Intendencia - Causas Administrativas Ordinarias. Leg. 51. Exp. 964: fol. 7v

1809 Serie: Notarial. Notario: Antonio del Solar. Leg. 52: fol. 147-148v

1809 Serie: Notarial. Notario: Antonio del Solar. Leg. 52: fol. 236v

1809 Serie: Notarial. Notario: Antonio del Solar. Leg. 52: fols. 238, 315, 344

1810 Serie: Notarial. Notario: Antonio del Solar. Leg. 53: fol. 3-3v

1812 Serie: Notarial. Notario: Antonio del Solar. Leg. 55: fol. 447

1812 Serie: Notarial. Notario: Antonio del Solar. Leg. 55. Prot. 10

1814 Serie: Notarial. Notario: Antonio del Solar. Leg. 56: fol. 53-54 
1815 Serie: Notarial. Leg. 57: fol. 179v-182, fol. 298-309

1816 Serie: Notarial. Leg. 58: fol. 229v-234v

1821 Serie: Gobierno Político y Militar - Causas civiles. Leg. 2. Exp. 28

1821 Serie: Notarial. Notario: Manuel Rebolledo. Leg. 1: fol. 32

1821 Serie: Notarial. Notario: Manuel Rebolledo. Leg. 1. Prot. 5

1821 Serie: Notarial. Notario: Manuel Rebolledo. Leg. 1. Prot. 5: fol. 123

1825 Serie: Notarial. Notario: Manuel Rebolledo. Leg. 5: fol. 21v

1826 Serie: Gobierno Político y Militar - Causas civiles. Leg. 2. Exp. 28

1839 Serie: Notarial. Notario: Manuel de la Vega. Leg. 138: fol. 253

1839 Serie: Notarial. Notario: Manuel de la Vega. Prot. 138: fol. 254

1846 Serie: Juzgado de Primera Instancia - Causas Administrativas. Leg. 284. Exp. 6112: fol. 1

1855 Serie: Notarial. Notario: Manuel Rebolledo. Prot. 91: fol. 132

1856 Serie: Notarial. Expedientes protocolizados. Notario: Manuel Rebolledo. Leg. 4

\section{Archivo Vásquez de Velasco (AVV)}

1818 Piura, 14 de octubre

1853 Piura, Poder a D. Juan Bautista de Llano, vecino de Madrid, 7 de julio

\section{Biblioteca Nacional de Lima (BN)}

$1822 \quad$ D8411

1828 D10929

\section{Imprenta Republicana}

\section{Fuentes secundarias}

ALDANA, S., 1999 - Poderes de una región de frontera. Comercio y familia en el Norte (Piura, 1700-1830), 303 p.; Lima: Ediciones Panaca.

ALJOVÍN DE LOSADA, C. \& RIZO-PATRÓN BOYLÁN, P., 1998 - La élite nobiliaria de Trujillo de 1700 a 1830. In: El Norte en la Historia Regional Siglos XVIII-XIX (Scarlett O'Phelan Godoy \& Yves Saint-Geours, eds.): 241-293; Lima: IFEA-CIPCA.

AQUERRETA, S., 2001 - Negocios y finanzas en el siglo XVIII: la familia Goyeneche; Pamplona: EUNSA.

ANNA, T., 2003 - La caída del gobierno español en el Perú. El dilema de la independencia, 322 p.; Lima: IEP.

ARELLANO, J. M. de, 1958 - De las Incidencias ocurridas en la proclamación de la independencia de esta ciudad de Piura en el glorioso día cuatro de enero de 1821. In: Prosistas piuranos. Primer Festival del libro piurano; Lima.

BONILLA, H. \& SPALDING, K., 1981 - La independencia en el Perú, 240 p.; Lima: IEP. 
CAÑEDO-ARGÜELLES FÁBREGA, T., 2000 - Élites urbanas en el sur andino (y con respecto al mundo). La sociedad de Moquegua en el siglo XIX. In: Poder y Mentalidad en España e Iberoamérica (Enrique Martínez Ruíz, ed.): 223-256; Madrid: Universidad del Zulia (Venezuela), Universidad Complutense de Madrid.

CAÑEDO-ARGÜELLES FÁBREGA, T., 2004 - La sociedad urbana en el siglo XIX. Cuando Moquegua perdió el tren. In: Al sur del margen. Avatares y límites de una región postergada, Moquegua (Perú) (Teresa Cañedo-Argüelles Fábrega, ed.): 113-150; Madrid: IEP, CSIC.

DE LA BARRA, F. (ed.), 1971 - Colección Documental de la Independencia del Perú, t. VI, vols. 5-6; Lima: Comisión Nacional del Sesquicentenario de la Independencia del Perú.

DENEGRI LUNA, Félix (ed.), 1971 - Colección Documental de la Independencia del Perú, t. V, vols. 1-3, Lima: Comisión Nacional del Sesquicentenario de la Independencia del Perú.

DESLINDE DE MORROPÓN, Impreso por Miguel Vásquez, Piura, 1858. In: MORENO, Federico, 1890 - Apuntes para una memoria sobre el departamento de Piura, vol. 17; Lima: Imprenta de F. Masías y Ca.-Unión 317.

EGUIGUREN ESCUDERO, L. A., 1940 - Diccionario histórico-cronológico de la Universidad Real y Pontificia de San Marcos Crónica e investigación, t. I-III; Lima: Imprenta Torres Aguirre.

ELÍAS, J. (ed.), 1971-1972 - Colección Documental de la Independencia del Perú, t. VII, vols. 2-3; Lima: Comisión Nacional del Sesquicentenario de la Independencia del Perú.

ESPINOZA CLAUDIO, C., s.f. - Un movimiento agrarista en la Independencia de Piura: los colonos siervos de Morropón-Yapatera: 1820-1825, 36 p.; Piura: CIPCA.

GLAVE, L., 1993 - La Puerta del Perú: Paita y el extremo norte costeño, 1600-1615. In: Boletín del Instituto Francés de Estudios Andinos, 22 (2): 497-519; Lima.

HELGUERO SEMINARIO, F., 1974 - De la Patria Vieja (Antología de cuentos y leyendas piuranas), 126 p.; Piura: Universidad de Piura.

HERNÁNDEZ GARCÍA, R., 2003 - Las Cartas de Dote en la Historia Socio-Económica de Piura. Época Virreinal (1590-1819). Tesis de Maestría en Educación - Mención en Historia; Piura: Universidad de Piura (Inédita).

HERNÁNDEZ GARCÍA, E., 2005a - Estrategias de supervivencia de una élite regional: las familias piuranas (1780-1825). In: Élites urbanas en Hispanoamérica (De la conquista a la independencia) (Luis Navarro García, ed.): 435-450; Sevilla: Universidad de Sevilla.

HERNÁNDEZ GARCíA, E., 2005b - La Élite Piurana ante la Independencia del Perú. La Lucha por la continuidad en el tránsito hacia la República. Tesis doctoral; Navarra (Inédita).

HERNÁNDEZ GARCÍA, E., 2006 - Clérigos de provincia en busca de una prebenda: la lucha de los vecinos piuranos por una canonjía en el Perú tardocolonial (1780-1821). In: Estudios sobre clero iberoamericano, entre la independencia y el Estado-Nación (Valentina Ayrolo, ed.): 15-45; Salta: Centro Promocional de las Investigaciones en Historia y Antropología (CEPIHA), Editorial de la Universidad de Salta.

HERNÁNDEZ GARCÍA, E., (en prensa) - Vínculos de interés entre Piura y Lima: la relación de algunos vecinos piuranos con el Tribunal del Consulado limeño a fines del período virreinal. Revista Atril; Piura: Facultad de Ciencias de la Educación de la Universidad de Piura.

HOCQUENGUEM, A. M., 1998 - Para vencer la muerte. Piura y Tumbes, raíces en el bosque seco y en la selva alta - Horizontes en el Pacífico y en la Amazonía, 445 p.; Lima: IFEA, CNRS, INCAH. 
IZCUE, L. de, 1929 - La nobleza titulada en el Perú colonial, 16 p.; Lima: Empresa Editora Cervantes.

LYNCH, J., 1992 - Caudillos en Hispanoamérica, 569 p.; Madrid: Editorial Mapfre.

LOHMANN VILLENA, G., 1947 - Los americanos en las órdenes nobiliarias, t. I-II; Madrid: CSIC, Instituto Gonzalo Fernández de Oviedo.

LOHMANN VILLENA, G., 2004 - El secretario mayor de gobernación del virreinato del Perú. Notas para un estudio histórico-institucional. Revista Histórica, 41: 191-212; Lima.

MAZZEO DE VIVÓ, C. (ed.), 1999 - Los comerciantes limeños a fines del siglo XVIII. Capacidad y cohesión de una elite, 1750-1825, 240 p.; Lima: Pontificia Universidad Católica del Perú.

MC EVOY, C., 1997 - La utopía republicana: ideales y realidades en la formación de la cultura política peruana, 467 p.; Lima: Pontificia Universidad Católica del Perú.

MILLA BATRES, C., 1986 - Diccionario histórico y biográfico del Perú, t. IV, 400 p.; Lima: Editorial Milla Batres.

MOYA ESPINOSA, R., 1981-1984 - Breve historia de Piura (recortes periodísticos del diario «El Correo»), t. III: Virreinato.

O'PHELAN GODOY, S. (ed.), 2001 - La independencia en el Perú: de los Borbones a Bolívar, 542 p.; Lima: Pontificia Universidad Católica del Perú, Instituto Riva Agüero.

ORTíz DE ZEVALLOS, J., 1989 - El norte del Perú en la independencia: testimonios de San Martín, Bolívar, Torre Tagle, 188 p.; Lima: Centro de Documentación e Información Andina.

PONS MUZZO, G. (ed.), 1973-1975 - Colección Documental de la Independencia, t. XVI, vols. 1-3; Lima: Comisión Nacional del Sesquicentenario de la Independencia del Perú.

RAMOS SEMINARIO, I. \& GARRIDO LECCA FRÍAS, G., 1996 - San Miguel de Piura: vínculos de Sangre, 1650-1940, 221 p.; Piura.

REYES FLORES, A., 1999 - Hacendados y comerciantes. Piura-Chachapoyas-MoyobambaLamas-Maynas (1770-1820), 205 p.; Lima: Fondo Editorial de la Universidad Nacional Mayor de San Marcos.

RIZO-PATRÓN BOYLÁN, P., 2002 - Linaje, dote y poder: La nobleza de Lima de 1700 a 1850, 400 p.; Lima: Fondo Editorial de la Pontificia Universidad Católica del Perú.

TRAZEGNIES, F. de, 1945 - Los Vásquez de Velasco. Historia genealógica de una noble e ilustre familia española del Perú. Revista Histórica, 16: 7-41; Lima: Librería e Imprenta Gil.

TURISO SEBASTIÁN, J., 2002 - Comerciantes españoles en la Lima borbónica: anatomía de una élite de poder, 1701-1761, 379 p.; Valladolid: Universidad de Valladolid.

VARGAS UGARTE, R., 1965 - Títulos nobiliarios en el Perú, 8 p.; Lima: Librería e Imprenta Gil. 


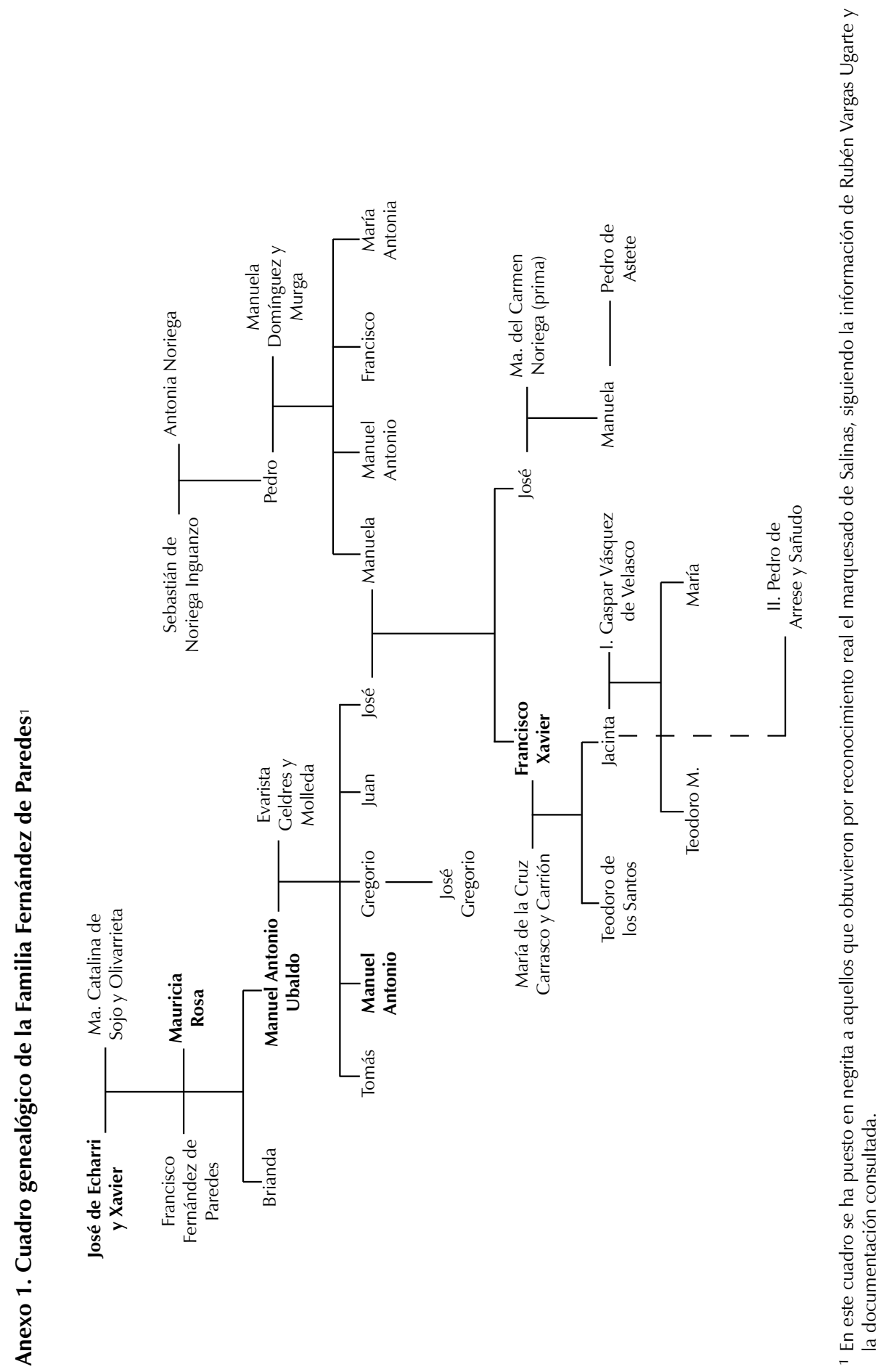




\section{Anexo 2. Bienes del Mayorazgo de Tomás Fernández de Paredes}

\begin{tabular}{|c|c|}
\hline Tierras y bienes inmuebles & Casas \\
\hline $\begin{array}{l}\text { Hacienda Tangarará (1773) vinculada en } \\
\text { sus tierras, casa, oficinas, aperos, ganados y } \\
\text { esclavos }\end{array}$ & Una casa Mayorazgo de Salinas en Lima \\
\hline $\begin{array}{l}\text { Tierras de la «otra banda» de Tangarará } \\
\text { denominadas «Sojo»»2 }\end{array}$ & Una casa en la calle Copacabana en Lima \\
\hline & $\begin{array}{l}\text { El solar del Pozo, a espaldas de la casa Mayorazgo } \\
\text { de Lima, vinculado en Francisco Javier Fernández } \\
\text { de Paredes }\end{array}$ \\
\hline \multicolumn{2}{|c|}{ Capellanías, legas y aniversarios } \\
\hline \multicolumn{2}{|c|}{$\begin{array}{l}\text { Aniversario patronato real de legos de } 10.000 \text { pesos sobre su hacienda de Tangarará (1793 ó } \\
\text { 1794) }\end{array}$} \\
\hline \multicolumn{2}{|c|}{$\begin{array}{l}2900 \text { pesos de una capellanía en la casa de la calle Copacabana a favor del presbítero D. Camilo } \\
\text { Cavero }\end{array}$} \\
\hline \multicolumn{2}{|c|}{$\begin{array}{l}\text { Principal de } 6000 \text { pesos de una capellanía lega sobre la casa de la calle Copacabana, fundada por } \\
\text { Da. Francisca de Salazar y Da. María Ignacia Clerque }\end{array}$} \\
\hline \multicolumn{2}{|c|}{ Capital invertido } \\
\hline \multicolumn{2}{|c|}{5000 pesos adeudados por Josefa de Silva, capital que heredó Juan Fernández de Paredes } \\
\hline $\begin{array}{l}48000 \text { pesos en escrituras de bienes heredad } \\
\text { de Paredes }\end{array}$ & e su padre Manuel Antonio Ubaldo Fe \\
\hline
\end{tabular}

\section{Anexo 3. Bienes del Mayorazgo de Francisco Javier Fernández de Paredes 3}

\begin{tabular}{|c|c|}
\hline Tierras y haciendas & Casas \\
\hline Hacienda de Morropón (Piura) & Casa nombrada «El Tamarindo» (Piura) \\
\hline Hacienda Tangarará (Piura) & $\begin{array}{l}\text { Una casa y un solar en el barrio de San Lázaro } \\
\text { (Lima) }\end{array}$ \\
\hline La chacra de Salinas (Lima) & $\begin{array}{l}\text { Tres tiendas y sus accesorios en el mismo barrio } \\
\text { (Lima) }\end{array}$ \\
\hline \multicolumn{2}{|c|}{ Capellanías, legas y aniversarios } \\
\hline \multicolumn{2}{|c|}{$\begin{array}{l}3000 \text { pesos que reconoce la casa denominada de Polanco que poseen los hijos de D. José Lasarten, } \\
\text { en la calle de La Merced (Lima) }\end{array}$} \\
\hline \multicolumn{2}{|c|}{6800 pesos fundada por Da. Mauricia Galde } \\
\hline \multicolumn{2}{|c|}{3350 pesos los reconoce Juan Bautista Lavalle, vecino de la ciudad de Lima } \\
\hline \multicolumn{2}{|c|}{3450 pesos reconoce el Tribunal del Consulado } \\
\hline \multicolumn{2}{|c|}{$\begin{array}{l}\text { Capellanía fundada por D. Juan de Moneda sobre la hacienda de San Regis propia de D. José } \\
\text { Carrillo, antiguo Conde de Monte-Blanco que impuso sobre dicha hacienda su antecesor y tío } \\
\text { Gregorio Fernández de Paredes (Lima) }\end{array}$} \\
\hline \multicolumn{2}{|c|}{$\begin{array}{l}2000 \text { pesos al } 3 \text { \% fundada por Da. Ana Maldonado sobre unas casitas abajo del puente, frente de } \\
\text { la Casa Mayorazgo de Salinas que posee el Convento de Santo Domingo (Lima) }\end{array}$} \\
\hline \multicolumn{2}{|c|}{$\begin{array}{l}\text { Un aniversario de } 6000 \text { pesos, impuestos al 3\%, fundado por Da. María Ignacia Clerque y Da. } \\
\text { Francisca Salazar sobre una casa en la calle de Copacabana en el Rímac (Lima) }\end{array}$} \\
\hline
\end{tabular}

2 Tomás dejó establecido que las tierras «Sojo», en las que vivían algunos colonos, pasado el tiempo y muertos los descendientes directos de estos, pasasen a formar parte de la hacienda Tangarará y estuviesen incluidos en el vínculo.

${ }^{3}$ ARP, 1839, serie: notarial. Notario: Manuel de la Vega. Prot. 138: fol. 254. 
El marqués de Salinas y su permanencia en la clase dirigente piurana a inicios de la República (1785-1839)

\section{Anexo 4. Bienes adquiridos durante el matrimonio Fernández de Paredes-Carrasco y} Carrión

\begin{tabular}{|l|l|}
\hline \multicolumn{1}{|c|}{ Bienes inmuebles } & \multicolumn{1}{|c|}{ Capital invertido } \\
\hline La hacienda «El Platanal» (Tumbes) & $\begin{array}{l}\text { Un principal de } 19271 \text { pesos comprados al } \\
\text { Estado, y que reconoce la chacra de Encalada y } \\
\text { una casa frente a Santo Domingo (Lima) }\end{array}$ \\
\hline La hacienda de Poechos (Piura) & $\begin{array}{l}\text { Otro principal de 14 850 pesos impuestos en las } \\
\text { fincas que posee D. Miguel Torres y Vásquez, } \\
\text { Conde que fue de Torre-Blanca, sobre una } \\
\text { casa calle de la Minería y sobre la hacienda de } \\
\text { Concón (Lima) }\end{array}$ \\
\hline La hacienda Pazul (Piura) & \\
\hline $\begin{array}{l}\text { Trozos de orillas y montes que se agregaron a la } \\
\text { hacienda Tangarará (Piura) }\end{array}$ & \\
\hline
\end{tabular}

